\title{
BEYOND GRIT AND RESILIENCE: HOW BLACK MEN IMPACTED BY THE CRACK EPIDEMIC SUCCEEDED AGAINST THE ODDS AND OBTAINED DOCTORAL DEGREES
}

\author{
As A dissertation submitted to the faculty of \\ 35 \\ 2019 \\ EDD \\ .$C 65$ \\ San Francisco State University \\ In partial fulfillment of \\ the requirements for \\ the Degree
}

Doctor of Education

In

Educational Leadership

by

Charles La Von Cole, III

San Francisco, California

May 2019 
Copyright by

Charles La Von Cole, III

2019 


\section{CERTIFICATION OF APPROVAL}

I certify that I have read How Black Men Impacted by the Crack Epidemic Succeeded Against the Odds to Obtain Doctoral Degrees by Charles La Von Cole, III, and that in my opinion this work meets the criteria for approving a thesis submitted in partial fulfillment of the requirement for the degree of Doctorate of Education in Educational Leadership at San Francisco State University.
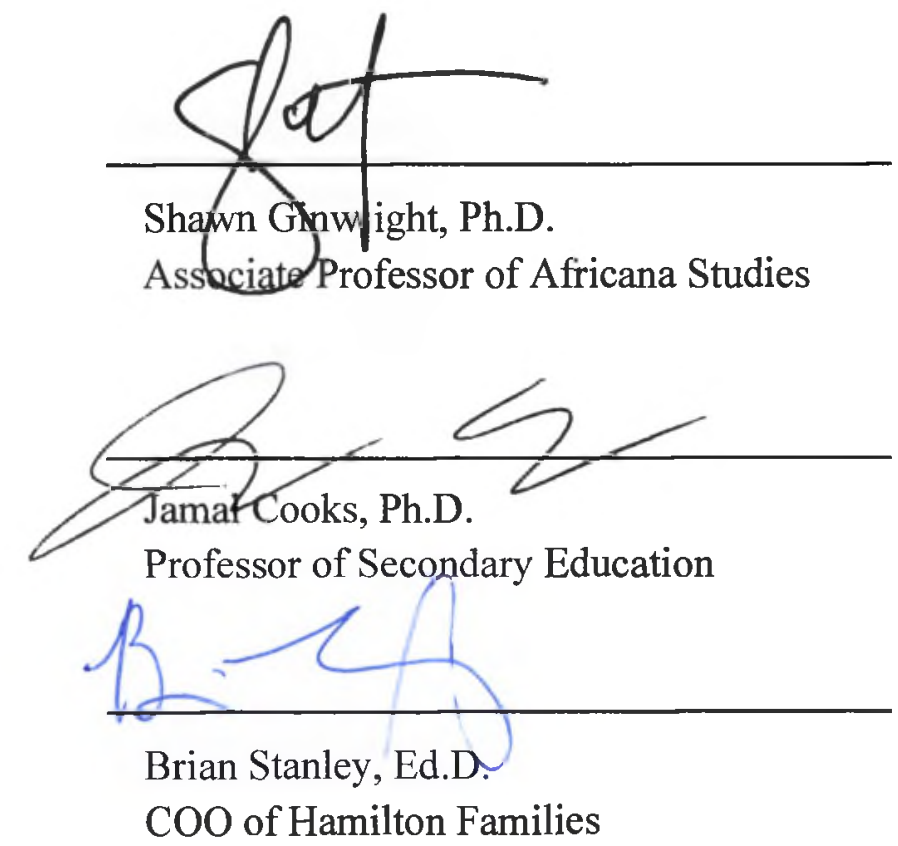


\title{
BEYOND GRIT AND RESILIENCE: HOW BLACK MEN IMPACTED BY THE CRACK EPIDEMIC SUCCEED AGAINST THE ODDS AND OBTAINED DOCTORAL DEGREES
}

\author{
Charles La Von Cole, III \\ San Francisco, California
}

2019

This comparative case study utilized oral histories to illuminate the life stories of three Black men who grew up impacted by the crack epidemic and the attendant traumas. The goal of the study was to better understand how they navigated education and life experiences to eventually earn doctoral degrees, and the social-emotional residual impacts that came from such navigation. The findings affirm and illuminate the lives of these Black men. The key findings are that they navigated by (a) seeking out quality education, (b) developing strong self-agency, and (c) utilizing close proximity to success. The study also found findings that suggest these Black males who grew up in highly stressful circumstances still experience strong residual effects of their early traumatic experiences which are exacerbated as a result of the navigation process required of them to achieve high academic attainment success, better known as the Black Achievement Trauma Tax. The study concludes that the key to increasing the rate of academic success among Black males is reducing the effects of trauma and provides recommendations for how communities and schools can achieve this. The lives of the men in this study illustrate that with the right support to promote healing from the effects of trauma Black males can overcome the most traumatic experiences and achieve academically at the highest level. However, when healing does not accompany the journey to academic success it comes at a cost.

I certify that the abstract ispa correct representation of the content of this dissertation.

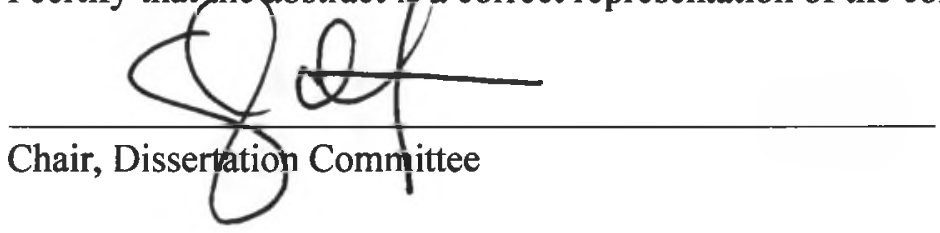

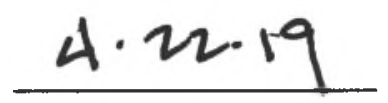

Date 


\section{PREFACE AND/OR ACKNOWLEDGEMENTS}

This dissertation is dedicated to my favorite gal in the world, my grandmother Ozetta Hooper. Rest soundly in Heaven.

To my brother, Will Jackson, and the block that raised us, $54^{\text {th }}$ and Gaskill, North Oakland. That block taught us that nothing or nowhere defines us but us. That neighborhood built us to be strong and leave a mark. To Mathaline, Frank, and Terry, who run the One of All Barbershop in North Oakland, for showing me what Black entrepreneurs look like.

To my parents, Charles, Jr., and Renate Cole for doing the best they could with what they had. Regardless of where life has taken you, you will from this day forth be able to say you raised a doctor, and none of this would be possible without either of you. You owe zero apologies to this world.

To Jeff, Mr. and Mrs. Corbin, the old homies alive and passed on, that spent time in that house on $37^{\text {th }}$ in West Oakland. Without that house and those people, I would not have finished undergrad.

To my dissertation committee. To Dr. Ginwright, for your unwavering support, guidance, and brilliance. To Drs. Brian and Jamal for pushing me throughout and being both critical colleagues and friends. Also, to Don and Stan for coming through in the clutch.

Finally, to the memory of the real-life versions of my pseudonyms, Donald (Tank) and Demarcus, RIP. There is no way I am on this path without either of you. Bless up! 


\section{TABLE OF CONTENTS}

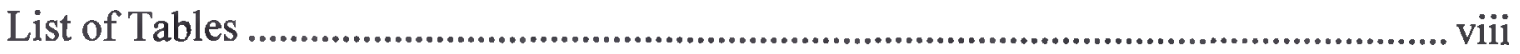

List of Appendices ........................................................................................................... ix

Chapter 1: Introduction ....................................................................................................

Purpose of Study .............................................................................................................5

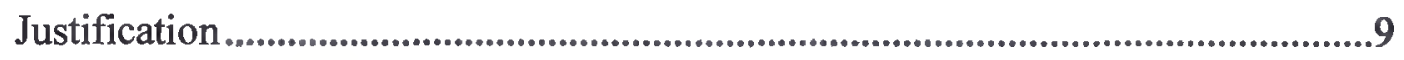

Chapter 2: Literature Review................................................................................11

Culture Deficit vs. Systemic Issue: Black Boy as Issue .........................................12

Navigational Skills of Black Males who Succeed Academically .............................14

The Context of Grit.........................................................................................

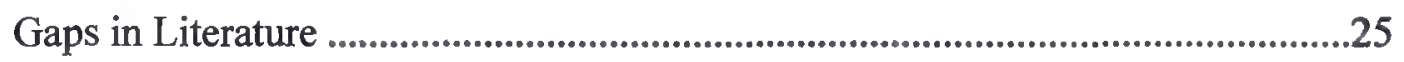

Research Questions .......................................................................................................26

Chapter 3: Methods ...................................................................................................................28

Research Design................................................................................................................28

Recruitment and Selections...............................................................................

Profile Requirements for Subjects ............................................................................34

Oral History Interview Data Processing ..................................................................36

Chapter 4: Oral Histories......................................................................................................38

Demarcus, Brooklyn .......................................................................................................39

Donald, East Oakland ..........................................................................................................64

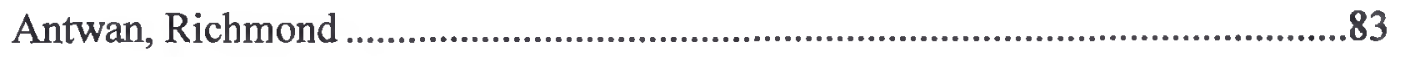




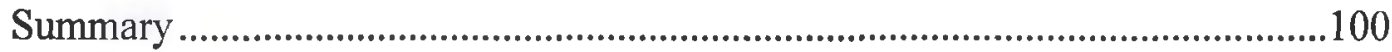

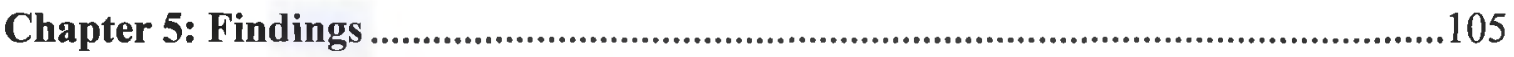

Restating the Purpose of Study .......................................................................105

Summary of Findings...................................................................................................105

The Black Achievement Trauma Tax Phenomenon ..............................................114

Implications for Research ......................................................................117

Recommendations for Future Research........................................................122

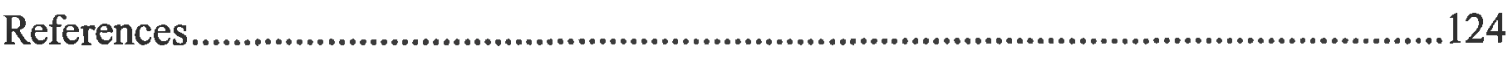

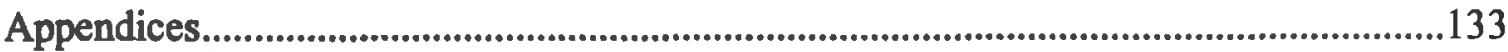




\section{LIST OF TABLES}

Table

1. Table 3.1: Oral History Breakdown........................................................................30

2. Table 3.2: Participant Profiles............................................................................32

3. Table 3.3: Black Academic Trauma Tax Phenomenon................................................116 


\section{LIST OF APPENDICES}

$\begin{array}{lll}\text { Appendix } & \text { Page }\end{array}$

1. Implied Consent to Participants in Research.....................................................125

2. Dissertation Study Survey Application..............................................................126

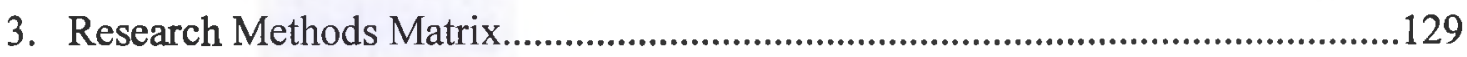

4. Navigation Strategies Individual Summary ...........................................................133 


\section{Chapter 1: Introduction}

Research on Black males over the past decade has created a pervasive set of ideas that Black men are a difficult group to educate. The growing body of research fails to illuminate the pro-social attributes and strengths of Black men who succeed academically. This dissertation aims to identify the strengths that doctoral Black males have along their educational journey explored via oral histories while also illuminating the resulting residual impact of that journey.

These stories of triumph are essential and sharing them is powerful. I know because I lived it. In the early 1990s, I was 11 years old and enrolled in my 11th school, at least this is my estimate as I sat down and attempted to recall my arduous journey. The backdrop of my life during this time was the crack (cocaine) era. This drug epidemic was prevalent in every place I lived throughout the country from Chicago to Kentucky. My parents struggled with both crack cocaine addiction and incarceration. We were living in Chicago a few months before that. When we moved to California, my mother was stuck in a Kentucky jail. She met us in California when she was released. I remember when we moved into our second shelter. This particular shelter had a weird smell, the food was disgusting, and I hated having to dig for clothes in the donation bin. I hated it, and I hated everyone and everything around me. I remember my mother telling me she felt her life would've been different had she gone to college. In the mornings, I would wake up and get my baby sister dressed and fed; she was three years old. I would also get my brother dressed and ready for school, and we would all leave the shelter and take the Bay Area 
Rapid Transit train over to Oakland to school. At this point, I had a weird balance of love and disdain for my parents. Even at a young age, I felt responsible for my education. I felt like it was my only path toward changing my life circumstances. One day in 6th grade, I overheard the secretary in the school office say that this school was full of future criminals - I hated everybody at that school. It was at that point that I had committed to going to college no matter what.

In 1997, the summer heading into high school, one of my best friends from middle school was murdered the summer heading into high school. Then, more people I grew up with started dying. In 1999, my sophomore year in high school, I learned a valuable lesson: if I could outwork the people around me, be consistent and maintain a grade point average at the 20 percentile of my school and take these classes called "Advanced Placement," I could potentially go to college.

I asked my high school counselor for assistance, but she refused to make time for me. I went to her office daily for almost a week. Frustrated, one day, I went to her office without for asking permission from my teacher and sat down. I was told that I would get detention, but I did not care. I just waited. We finally spoke, and I told her I had to go to college. I told her I would outwork everyone around me. She made changes to my coursework, and I kept a decent GPA. I started reading about California State Universities (CSUs); the pamphlet said if I maintained a 3.0 GPA my SAT scores were not critical to my admittance. I earned the 3.0 GPA; I filled out all my applications myself. I did not focus on the schools I really wanted to go to, but rather applied to the 
schools I thought I had the best chance of getting into. The school just had to have 'university' in the name. While I was filling out college applications, more friends following paths leading to death.

In 2001, I was accepted to California State University, Hayward. I knew I would outwork everyone to succeed. In 2005, I earned a bachelor's degree in 2005. I earned my master's degree in Public Administration in 2010 and then 2015, I was admitted to the doctoral program at San Francisco State University. The same way I worked angrily at age 11 is the same way I work angry today. Was this grit or something else? Also, despite my academic success, was other damage done? There are others like me. What do we credit our academic success to? What has my generation learned from our struggles that we now apply to future endeavors?

While in the doctoral program, I became curious about my own pathway toward obtaining a graduate degree. I wanted to better understand how the opportunities, decisions, and mentoring made a difference in my own quest for a doctoral degree. To understand potential success strategies for Black families, it is critical to identify the opportunities and tactics that make a difference in Black male academic success. Researchers have attributed the push that successfully moved me along my academic pathway to academic success to grit, the idea that I persevered because of my powerful passion for my long-term goals (Duckworth, Peterson, Matthews, \& Kelly, 2007). While true in part, it is an inadequate summation of what I endured to accomplish my goals. To say that my perseverance was solely due to grit erases my story and the evidence of 
centuries of systemic racism and oppression that conditioned the educational landscape to be what it is today. Also, attributing all success to grit does not speak to the residual impacts of constantly battling trauma and adversity has on my psyche now. What is the true cost of the highest of academic attainment for Black folks that grew up in hell? It is critical to explore the stories of other Black males that have reached the highest level of academic success because not to do so condemns more Black children to the lie that they do not have Black male superheroes living in their very communities.

This dissertation begins by explaining the purpose of this study, including exploring and justifying the need for the study's existence and entre into the education lexicon. Then, this dissertation will explore the literature to better situate how Black males and their struggles have been researched, captured, and interpreted over the last 30 years. This dissertation will thoroughly explain the importance of using a comparative case study research design that utilizes oral histories and in-depth interviews to engage this study's research questions.

The data gathered from the three Black men in the study uncovers a phenomenon, which I have called the Black Academic Trauma Tax (BATT). BATT, is the phenomenon wherein people grew up in poverty and experienced high volumes of trauma but nonetheless successfully navigated education without actively addressing their traumas pay a great social-emotional price. This continues to be true even for Black males who have achieved the highest levels of academic success-earned doctorates. The BATT phenomenon is further discussed in Chapter 5. 


\section{Purpose of Study}

The purpose of this study is threefold; (1) to examine the strategies and navigation skills of three Black males, who against all odds, successfully navigated public education to attain a doctoral degree; (2) to identify and understand the social-emotional residual impacts that can come from such navigation; and (3) to affirm and illuminate the lives of Black males that have succeeded academically.

\section{Theoretical background on why Black men succeed or fail.}

The crack epidemic had a huge impact on Black communities, and more specifically Black children. Between 1984 and 1990, America witnessed a significant rise in adult exposure to crack cocaine use (Fryer, Heaton, Levitt, \& Murphy, 2013). Additionally, during this period, there was an aggressive shift in how Black males were treated in K-12 schools that consequentially negatively impacted academic achievement, completion rates, and potentially influenced increases in incarceration. All of which are still experienced today. Students exposed to suspensions are at a higher risk of dropping out of school. Black people represent five percent of California's K-12 student population, yet account for $18 \%$ of all the state's K-12 suspensions with Black males receiving $75 \%$ of those suspensions; alarmingly, Black males are 3.6 times more likely to be suspended than the state's average. Also of interest, Black males in foster care have a suspension rate of $27 \%$ (Harris III \& Wood, 2013). There is a strong relationship between suspension, incarceration rates and the crack era (Fryer, Heaton, Levitt, \& Murphy, 2013). 
During the late 1980 s, a series of laws increased the likelihood of young Black men being incarcerated. For example, the Anti-Drug Abuse act of 1986 mandated that crack dealers and users receive mandatory minimums - with drug use on the rise, the consequences of this legislation were long-lasting and proved to be critical. Between 1984 and 1994, in addition to increased suspension rates for Black males, the homicide rate for Black males skyrocketed. Homicide rates for Black males aged 14-17 more than doubled while rates for Black males age 18-24 grew just under 50\% (Fryer, Heaton, Levitt, \& Murphy, 2013). As would be expected based on the hardships and injustice, the academic achievement for Blacks (relative to whites) broke from decades of convergence, and the academic achievement gap grew in the late 1980s and early 1990s (Fryer, Heaton, Levitt, \& Murphy, 2013). These impacts persist, and Black males still have the highest suspension rate, are at the bottom of academic achievement, have the highest suspension rate, and are disproportionately to this day, still pushed out of school at alarming rates (Duncan, 2002; Duncan-Andrade \& Morrell, 2008; Noguera, 2003, 2012). Despite the challenges, Black males with terminal degrees that attended school during this era have earned terminal degrees and thus offer a hopeful perspective.

\section{Examining the strategies of successful Black males.}

There is a lack of research that examines the successful strategies used by Black males impacted by the crack era to overcome severe societal and systemic hurdles. By better understanding the strategies these academic scholars deployed, Black males and their families gain insight and resourcefulness. By thoroughly examining actual first-hand 
accounts, new strategies arise that are transferable to schools, community organizations, churches, community members and anyone else committed to increasing educational attainment of Black males. There is valuable social capital to be discovered and explored that many Black families struggling through the education system can rely on, deploy, and personalize (Bourdieu, 1986).

There is a relationship between poverty and agentic actions. Blacks have a history of coming together and displaying intense creativity and fortitude when attacked by racist systems. In their darkest times, Blacks have presented agentic actions, or actions that are strategic and survival-dependent, since their collective American history began. Many examples of Black strength, creativity and perseverance can be found during slavery. Since involuntarily emigrating from Africa to the United States, Blacks displayed endless creativity deeply rooted in resilience to survive as stolen people. For example, during the abusive institution of slavery, Blacks were given the worst parts of the animal that the white masters did not want and learned how to season it and prepare it not only to survive but to make slop delectable. This essentially and ultimately created what is today described as soul food (Covey \& Eisnach, 2009). During the same time, enslaved Africans were not able to worship in private without a white person in attendance. Since Christianity and prayer became a form hope for Blacks during slavery, the Black community created codes and secret meeting places where they could go pray and worship together in what would be called the Invisible Institution (Croft, 2017). Invisible Institutions would eventually become Praise Houses, and then the very churches that 
housed civil rights revolutions and became the pillar in thousands of communities still to this day (Croft, 2017). The Black church grew out of intense duress.

Similarly, this study will examine how Black men act as agents rather than mere subjects to specific forms of marginalization. In this study, I am proposing a close examination of the methods Blacks build and emphasize in this time of academic duress. This study will explore what, in the field of education with its abysmal track record of educating Black males, successful Blacks bore out of poverty to reach the highest levels of educational attainment have created and deployed out of pure necessity. The knowledge and understanding of the actions Black academics took will help Blacks excel in education at scale.

Of great importance, this study aims to illuminate and affirm the lives of Black males. This study situates Black males affirmatively by examining their strengths and triumphs which is in direct contrast to academic articles that focus on Black males as problematic, violent, inadequate, and the like (Harper, 2015; Brooms, 2015; LadsonBillings, 2007; McGee, 2013; Noguera, 2003; Wald \& Losen, 2003). Harper argues that academia largely reinforces negative notions about Black males which ultimately adds implicit bias and institutional racism against them (2015). By focusing on three Black males that have attained terminal degrees, the highest level of education in their specific field, the study starts from a place of strength. 


\section{Justification}

Current research explains how poorly Black males perform in public school and in life compared to other groups (Duncan, 2002; Duncan-Andrade \& Morrell, 2008; Noguera, 2003, 2012). There have been education reform efforts for decades that resulted in little gains for Black males (Noguera, 2003). Black males are still the highest incarcerated group in America despite Black Americans comprising less than 13\% of all citizens (Fryer, Heaton, Levitt, \& Murphy, 2013). Specific research links the high levels at which Black males are pushed out of K-12 schools directly to higher incarceration percentages for Black males (Harris III \& Wood, 2013). This level of failure in our country and the various systems listed, whether it be education, prison, or healthcare, is a civil rights issue and an equity issue because these failures aid in the dismissal of Black males as intelligent, humane people. One only needs to watch the news or read the headlines to witness the constant dehumanization of Black males.

By taking a more in-depth look at three different stories of Black males overcoming the odds, examining how they accomplished their educational goals, and sharing that information, four goals were accomplished. First, it demystified how Black men that grew up in severe trauma navigated their educational journeys to earn doctoral degrees. Second, these stories explored the true social-emotional cost of attaining this such high levels of academic success. Third, by allowing these Black males to tell their stories, they were humanized, and their experiences offered great insight, much more than a quantifiable survey alone. Finally, for the men telling their stories, this was an 
opportunity for them to reflect on their triumphs in a world where a Black male may not feel like he has many of those. This research paper will honor and salute these men by sharing their stories. Black males impacted by the crack epidemic that went on to earn doctorates deserve their own acclaim that captures their humanity since the chances of them simply going to college and staying out of jail was so diminutive. These Black males all deserve to be someone's hero if not only for the fact that they prove academic success is possible for Black males and we have three shining examples. 


\section{Chapter 2: Literature}

Understanding the perceptions Black male students must face while also utilizing a variety of potential navigational skills is imperative to improving educational

attainment. This literature review starts by exploring the three primary schools of thought regarding Black male achievement in schools. First, the role of culture in academic achievement is investigated. The second school of examines explores the ways in which academic achievement is shaped by systemic barriers to success. The third section of this review details the role of social-emotional dimension of learning for Black students. The fourth section of this defines and examines grit in the context of social and emotional learning (SEL) and explores its relationship to academic achievement. Finally, this review discusses gaps in the literature.

\section{The role of culture on academic achievement for Black students}

Who is to blame for poor academic achievement amongst Black males; their culture or the system? After discussing the foundation of who or what is ultimately responsible, this review moves into the topic of navigational skills Black males who have risen from dire circumstances to high academic achievement have used. After exploring the navigation skills Black students may need to thrive academically, this literature review examines just how impactful grit is amongst students in urban public schools. Since grit has become such a popular form of intervention in urban public schools across America, this must be understood in terms of just how impactful it has been on students. 
In preparing this literature review, the focus was on research that addresses grit and academic achievement Is there strong evidence that grit could predict academic achievement? What impact does grit have on Black students specifically?

\section{Cultural Deficit vs. Systemic Issue: Black Boy as Issue or Broken System}

Whenever the issue of Black male academic achievement comes up, there are usually two schools of thought, cultural deficit model or broken systemic structures that aim at them. The cultural deficit model was popularized by John Ogbu, who argues that Black culture rejects upwardly mobile cultural norms such as valuing education and learning proper language utilized by the dominant culture (1995). Ogbu conducted a twoyear ethnography where he compared Chinese American and Black students in Oakland, CA. He conducted more than 30 parent interviews and 76 student interviews in each community as he aimed to learn about the cultural and language problems each group experienced in school and how they managed to deal with it. Ogbu concluded that Black students suffered from being part of an oppositional culture that ultimately viewed school and educational attainment as negative (acting white, selling out) while the Chinese American students embraced "upward mobility culture" and handily outperformed the Black students.

Ogbu's philosophy and focus on culture is popular, often being utilized by other researchers and prominent figures. One of the more famous examples of this ideology being used is the highly publicized Pound Cake Speech by Dr. Bill Cosby. The now infamous speech touched on the significant tenants from Ogbu's study specifically 
without naming him. Dr. Cosby warned that this is not a white problem, it is a [Black] problem. Dr. Cosby charged that Black mothers could pay $\$ 500$ for tennis shoes but not Hooked on Phonics, then in the next stanza, he says Black men do not want to be fathers (Cosby, 2004). Dr. Cosby gave cultural deficit one of the largest platforms it could have. It is important to note that there were scores of clapping and cheering throughout his speech. What Dr. Cosby perceived to be Black culture was, in his eyes, ignorant, selfdestructive, and ultimately not the white man's [read: the system's] fault.

Akom (2003) rejected the notion that Black students adopt oppositional culture. He too conducted a two-year study where he interviewed $50 \mathrm{~K}-12$ students, ten teachers, six community members, and two administrators. What he found was oppositional culture could have quite the opposite impact. He reported on a group of Black students from the Nation of Islam that wholly rejected "white, dominant culture" yet achieved at very high levels (Akom, 2003). These students did not see Blackness or Black culture as something to abandon or temper, but quite the opposite. When asked, one of the Nation of Islam girls described dominant white culture as stealing and being unethical. The girls from this study created study groups and were amongst the highest achievers in the school. Akom also noted that the school was dysfunctional and despite this, guided cultural and social resources within an ethnic community can increase the chance of educational attainment (Akom, 2003).

What Akom highlights is culture, when affirmed, and systems, when called out as dysfunctional, can work in tandem to help students build the agency and critical 
consciousness discussed earlier. By having a school, an adult, a system and the like, acknowledge its shortcomings, it is this researcher's theoretical belief that the constant stress experienced by Akom's subjects could have been avoided. However, this is where the need for self-repair surfaces. What the research does not explicitly address is the emotional and psychological toll it takes on a child: having to fight for the self-respect and dignity they deserve even when a system operated by individual human actors are daily potentially breaking down a child's hope daily.

\section{Navigational Skills of Black Males who Succeed Academically}

Research has shown that critical consciousness, the ability to analyze systemic issues (Freire, 1973), is an important component of learning for Black students. In the literature on what makes some Black students successful and how they navigate public education despite a harsh ecological system, there is a strand of research where students showed high levels of critical consciousness. This consciousness ultimately led to a level of self-agency, or as Freire (1973) calls an in-depth understanding of the world and context in which one exists. In the literature reviewed, the Black students featured displayed a strong understanding of systems of inequity in their schools and were able to adjust to achieve academically (Gutman \& Mcloyd, 2000; Land, Mixon, Butcher, \& Harris, 2014; McGee, 2013; Sheppard, 2006). Across these articles, many of the students lived in high-poverty neighborhoods in single-parent homes. Coupled with understanding the greater systemic forces working against them, these students were able to articulate an inner purpose, maintain close relationships with their families, utilize adult support, and 
possess a strong inner-will to succeed academically (Gutman \& Mcloyd, 2000; Land et al., 2014; McGee, 2013; Sheppard, 2006). In other words, the students demonstrated how critical consciousness guides Black students to a myriad of strategies that help them achieve academically despite the inadequacy of the school systems they often attend. In their educational ecosystem, Black students that succeed are forced to be strategic in their critical consciousness by assessing a world they live in which they are often seen as dangerous and less intellectually capable than their non-Black counterparts. Similar to what McGee (2013) found regarding students having to "come off less threatening", Sheppard's (2006) findings were complementary as they showed that some successful Black youth are forced in their everyday lives to juxtapose the role of young high achiever and being viewed as a threat. There were no conversations with other adults within the culture and environment as the boys still struggled to manage their ecosystem.

Like the studies conducted by Land et al. (2014) and McGee (2013), Sheppard's findings also show that students credited their success to their ability to focus, desire to succeed, self-determination, and support of each other. An essential contribution of Sheppard's research is the way it displays how Black youth with a firm belief in self and aware of broader systemic issues are less deterred by external factors because they understand that their circumstances are not their fault nor are they just random. Some may argue this is a definite showing of grit, and it is; however, it displays the mastery of essential navigation skills needed to be successful. 
Agency is the capacity of individuals to act independently and make their own free choices (Vermeesch \& Crabbe, 2015). Academic agency is the ability of students to exercise choices over their academic experiences (Berridge, 2017). There are factors that go into building the academic agency of a student. The students from the aforementioned literature developed and deployed strong academic agency as they made independent choices that led to higher academic outcomes.

However, the concept of academic agency alone may lead a student to internalize academic shortcomings without taking into account the often inadequate school or system. Therefore, Black students that display academic agency potentially fall into blaming themselves when systemic failures interrupt their academic progress. Simply put, there are root causes of circumstances, and the more a Black boy is made aware of them, the more agency he can form. Without conscientization or the understanding that there are actual reasons why their environment may be troubled and their schools regularly in shambles, Black males are more susceptible to rationalizing that their circumstances are random; this can lead students to feel like they are simply cursed. By leaning solely on grit in these circumstances, the demagoguery of the notion to "just work harder" is not only insulting but can also be damaging. For clarity, hard work and delayed gratification are still needed, however when critical consciousness is present, it allows for the root causes of systemic suffering to remain in the conversation.

Many Black students succeed despite adverse occurrences in their socialecological systems (Bronfenbrenner, 1986) in large part by gaining meaning and internal 
purpose developed from their lived experience (Land et al., 2014; McGee, 2013); it was never grit alone. The students in the study displayed a level of purpose that speaks to their lived experiences in a way that illuminates a sense of identity for embattled students. The youth described the spiritual strength that gave them the power to live a life of purpose, to persevere through adversity, and to accomplish a self-determined goal. This in combination helped them utilize their environment, making that which may be seen as a detriment become an asset. They saw themselves amid environmental factors that were not random, but systematically targeting their kind and felt a stronger sense of duty to be successful. Students in Land et al.'s (2014) phenomenological study overwhelmingly pointed to either a religious requirement of purpose on one's life or an inner purpose that stretched beyond their current existence.

Another tactic that students use to develop agency is by changing their appearance (example: dressing preppy) and making their school community feel more "comfortable" to gain the support they needed (McGee, 2013). While the students recognized this tactic was awkward at times, they made it clear that it was a prioritization choice that would lead to the desired goal and make their families proud. The students also knew the tactic would work because of how adults within their school environment viewed them. This strategy forces a child to deny a part of his or her identity while assimilating to the dominant culture. What may be an unfair mandate on a Black male, the desire to make their families, especially their mothers, proud seems to support critical consciousness (McGee, 2013; Land, et al., 2014). In many of the interviews, the students 
lived in single-parent homes or with grandparents. Throughout though, students made it a point to reference their mother.

In the above situation, these students showed strong signs of academic agency through their independent decision making and their ability to utilize their critical consciousness to discern what was in their control and being aware of what systemic factors were out of their control. The ability to practice academic agency at such a high level allowed the students to develop and support a deep inner motivation to succeed, which can be viewed as an overarching frame for understanding what drove their success. The critical consciousness in this instance played out when the students articulated the circumstances they needed personally for them to be successful (McGee, 2013; Land et al., 2014). This consciousness led these successful Black students to develop an awareness of the oppression they were facing and then have the agency to make tactical decisions to disrupt the systemic inequity to be successful. This perspective prepared them mentally for the struggle to succeed in a broken system. For these students, just by being successful and making it to and through college was a disruption of the systemic inequality they were facing.

\section{The Context of Grit and its Effect on Academic Achievement}

In the past decade, the term grit has become a popular term often utilized to communicate a set of skills that students, with an emphasis on Black boys, in urban school settings should embrace to attain academic success (Crede, Tynan, \& Harms, 2016). Grit is defined as "perseverance and passion for long-term goals" (Duckworth, 
Peterson, Matthews, \& Kelly, 2007, p. 1087). It requires that students not just be resilient in the face of adversity but demonstrate this tenacity over the course of years (Duckworth et al., 2007). Duckworth argues that grit can help explain the success on individual levels, name dropping scholars such as Albert Einstein (Crede, Tynan, \& Harms, 2016).

Duckworth et al. (2007) goes on to argue that grit is an equal or better determinate of success than cognitive ability (Crede et al., 2016).

Grit has been a dominant motivator in the development of successful school programs because it focuses on factors students and family can more readily control such as willpower and self-control (Duckworth \& Gross, 2014). The notion that a student's success is influenced by factors actively controlled versus other such as socioeconomic factors and systemic oppression is powerful in shifting mindsets from that of victimization to that of a driver of success. Grit, utilized appropriately, can build agency amongst students, parents, and community supporters when they feel a sense of ownership of achieving desired outcomes academically. For instance, when students build coping mechanisms and strategies that help them persist to achieve a larger goal, it displays a tenant of grit, the ability to persevere and not view early shortcomings as a failure but as part of a longer process (Duckworth \& Gross, 2014).

The term grit, popularized by Angela Duckwork (2007), is one element of a broader discussion about the significance of the value of non-cognitive domains of academic development for children. Grit is situated in what Paul Tough describes as noncognitive skills (2016). Noncognitive skills are the skills that cannot be tracked on an 
assignment or standardized tests. The skills, as defined by Tough are resilience, conscientiousness, optimism, self-control, and finally grit. Tough argues that while a teacher may not be able to teach "grit", she can teach a student how to act gritty, which can help yield academic gains. He argues that a teacher and school environment must build up academic perseverance in students, or the ability to continue moving forward despite setbacks (Tough, 2016). It is essential to understand the broader context in which grit exists.

Grit is situated within social-emotional learning (SEL), or the process through which children acquire and effectively apply the knowledge, attitudes, and skills necessary to understand and manage emotions, set and achieve positive goals, feel and show empathy for others, establish and maintain positive relationships, and make responsible decision (Wilkinson, 2014). However, much like grit within its model, SEL is limited and can exacerbate racist practices against Black males because it focuses on the individual rather than the systemic effort without taking into account the opportunity, or lack thereof to begin with, and the skill without examining who has the power. SEL as a whole perpetuates a colorblind, poverty-blind, and social context-less existence for Black males and does not force educational leaders to confront the overall environment leading to the acute way grit adds to the pervasion of how Black males are failed.

Grit, much like SEL, does not call into question the potential harm of just powering through problems over and over can have both instantly and down the line in the life of Black males who wholly adopt the concept. The notion caught on, especially in 
schools that worked with Black and Brown students and has been discussed in the national education lexicon as a "potentially novel predictor and determinate of performance" (Crede et al., 2016, p. 492). While research suggests the benefits of grit, we still understand very little about how grit hinders learning and growth. In this literature review, it is important to consider how grit does not take social context into account. The damage that is associated with this omission is of great significance. The research reviewed also explores the role critical consciousness plays in better understanding just how fine grit is as a concept for Black male students still required to survive the poor social conditions that threaten them daily.

This review of literature critiques grit while also examining the shortcomings and potential dangers associated with the broad stroke in which grit is sometimes painted and applied. Often, Black students lose parts of themselves including a contextual basis (Bronfenbrenner, 1986), strong self-identity, agency (Gutman \& Mcloyd, 2000; Land, Mixon, Butcher, \& Harris, 2014; McGee, 2013; Sheppard, 2006) and cultural strengths (Brooms, 2015; Harris \& Graves, 2010; Jordan \& Wilson, 2015). The grit conversation continues to perpetuate a negative master narrative (Harper, 2015; Harris, Hines, Kelly, \& Bagley, 2014; Johnson, 2017) as it is essentially rooted in antiblackness as a school practice (Dumas, 2015) that continues to castigate Black boys to being a group needing pity more than a good educational opportunity. 


\section{Grit lacks social context and is harmful without it.}

As mentioned above, grit as a concept reflects a broader discussion on socialemotional learning. Grit, as it has been popularized, presents as a color-blind solution, which is a myth that functions to erase the racial and socioeconomic realities that often plague Black boys in American public schools (Spencer, 2008), and does not take into account the framework of social-ecological systems (Bronfenbrenner, 1986).

Bronfenbrenner's framework details the five systems that play a large part in how social context impacts a child at any given moment, many of which are out of the control of the individual. The five systems include the microsystem, mesosystem, exosystem, macrosystem, and chronosystem. The microsystem represents the system closest to the person and those he or she has have direct contact with such as the family or teachers. The mesosystem represents the interactions between different players in the microsystem, for example, a teacher and parent conversing. The exosystem is the setting that does not directly involve the person in question but affects them, nonetheless. The macrosystem represents the cultural environment in which individuals live. The chronosystem represents two areas, the first being the dimension of time in relation to the person's development (e.g., a tragedy happening to a child versus happening to him as an adult) and the second being events that are unique to a particular generation (e.g., growing up during the Vietnam war is a different context than growing up in the 1990s).

The social-ecological model raises several critical questions about how grit contributes to the learning and development of children. Social and structural context 
shapes the quantity and quality of the grit needed for particular individuals - and grit in and of itself does not allow for that level of discernment. An example of this occurs in the 2007 study conducted by Stewart where she examined the relationship between academic achievement, the individual level, and the school structure. The study looked at 1238 African American students across 546 high schools, and while Stewart found that individual actions played a part in success, the structure of the school was also significant. Stewart concluded that students who attend schools with a supportive and inviting environment have significantly higher achievement (Stewart, 2007). The study explicitly stated that having a peer group that valued education, and strong support from their parents, teachers and school administrators are significant factors pertaining to success. According to Bronfenbrenner (1986), this type of support speaks to the mesosystem and macrosystem being activated positively and working to support the individual efforts of a student. If the structural support were absent, a student's individual will would have needed to be increased. However, grit does not provide the framework to discern how much more will or the potential toll that could be taken on a student. Frankly stated, grit and will alone significantly reduce the chances of academic success for the students in the study (Stewart, 2007).

\section{There is a lack of relationship between grit and academic achievement.}

There are a series of studies that found no relationship between grit and academic achievement in a variety of settings. Researchers found that grit had no impact on academic achievement in legal education (Zimmerman \& Brogan, 2015), science 
education in college (Bazelais, Lemay, \& Doleck, 2016), general college achievement (Chang, 2014; Wolters \& Hussein, 2015), and private high schools, (Ivcevic \& Brackett, 2014).

There were a series of articles that did find a significant relationship between grit and academic achievement, including the seminal study by Duckworth (Al-Mutawah \& Fateel, 2018; Duckworth, Peterson, Matthews, \& Kelly, 2007; Muenks, Wigfield, Yang, \& ONeal, 2017; Rimfeld, Kovas, Dale, \& Plomin, 2016; Strayhorn, 2014.) However, these studies found very small relationships that had no practical benefit as defined by Pogrow (2018; 2019). For example, in Duckworth's study, she found grit to be responsible for only $4 \%$ of the of the variance in successful outcomes. While $4 \%$ variance may be impactful in extreme circumstances such as an Olympic sprinter where any advantage makes a world of difference, the same cannot be said for Black students in urban schools living in poverty. Indeed, there are no studies on the relationship between grit and academic achievement in high poverty settings.

The literature search found no research that tested grit as an intervention. In addition, Prohl (2017) concluded that there is uncertainty on whether grit could be taught. Prohl concluded that while grit may not be able to be taught in a way that raises academic achievement, the components that make up grit can be reinforced in students that already possess grit.

In conclusion, there is no actual evidence that grit is related to academic achievement in a meaningful way or that it can or should be used as an intervention to 
improve academic performance. Nor was any evidence found that documented that Black students did not possess grit. This means that while grit presents itself as an evidencebased color-blind solution, given the absence of actual supporting evidence, it is racist to assume that Black students somehow do not possess grit and need to be taught it in schools. It is racist to present grit as an actual solution in the absence of evidence that it can increase the academic performance of Black students.

\section{Gaps in the Literature}

There is some evidence that successful Black male students have a high level of critical consciousness and agency that allows them to make calculated and strategic moves leading to academic achievement. Black male students are adept at incorporating the environmental factors into their decision making. The students' constant display of critical consciousness allows them to dispatch tactics with precision, not just blindly working or delaying gratification.

What the literature does not discuss is the potential psychological toll that pervasive miseducation ultimately takes on students when Black children not old enough to vote must deploy high levels of critical consciousness and agency with no notion of what level of assertion will be both successful and safe. Nor does the literature discuss how to properly heal these students from the psychological toll taken -- both as students and as adults. Nor does the literature discuss Black children, specifically those impacted by the crack epidemic which was one of the seminal forces that destroyed the Black community in many ways, in terms of the specific psychological traumas of growing up 
in that environment. The literature also does not discuss these successful students' lives post K-12 education nor does it discuss whether these strategies continued to be successful well into college and adulthood.

This literature also did not discuss how the successful students featured developed their high levels of critical consciousness or agency in sufficient detail. This literature does not discuss academic success beyond high school or college, nor does it discuss the issues these students may face into adulthood.

The study that follows is significant as it adds context to the gaps. This is the first study to look at the full life of Black men that have successfully navigated from an extremely traumatic background rooted in the crack epidemic to earn doctoral level degrees while exploring both the navigation strategies used and examining the residual social-emotional impacts plaguing them in adulthood. In order to address some of the gaps from the literature, the following research questions are utilized.

\section{Research Questions}

The purpose of this study is to examine the strategies and navigation skills of three Black males, who against all odds, successfully navigated public education to attain doctorate degrees.

The research questions are:

RQ1: What strategies enabled Black men impacted by the crack epidemic to survive public education and achieve doctorates? 
RQ2: What are the unanticipated social-emotional residual effects as a result of rigid academic achievement for Black boys? 


\section{Chapter 3: Methods}

This study utilized a comparative case study approach and was designed to examine the navigational strategies of three Black men that grew up impacted by the crack epidemic who now all possess doctoral degrees. Comparative case studies are the analysis and synthesis of similarities, differences, and patterns across two or more cases that share a common focus and are best used to answer research questions that essentially ask "how" or "why" (Goodrick, 2014). This study utilized the oral histories of three Black men with doctorate level degrees who grew up impacted by the crack epidemic. Oral history interviews helped to identify, highlight, and examine their navigation strategies during their distinct educational journeys. Oral histories were used to honor the African tradition of passing knowledge through storytelling. Oral histories took on even more personal significance as during times of slavery, Black people were not allowed to learn how to read or write.

In this section, there is first an overview of the methodology section. Following, is an overview of the research design and then the recruitment selection is described in the context of the study. Lastly, the data collection and data analysis processes are defined for this particular study.

\section{Research Design}

A comparative case study research design was used for this study. Comparative case studies are used to identify, analyze, and synthesize the differences, similarities, and various patterns in each individual study as well as across the selected studies (Goodrick, 
2014). For this study, background research was conducted on each participant to develop individual case studies. In addition to asking participants about their backgrounds, news articles and county reports were reviewed during the time era and geographic locations in which the participants lived. This method helped shape unique case studies for each participant. The goal of developing case studies was to better understand the nuanced impact and multifaceted traumatic experiences caused by living in high levels of poverty. Participants' narratives were most important for the development of their cases.

An audio recorder was used to capture the oral histories of participants. The goal of using oral histories of participants was to better understand the nuanced impact that traumatic experiences may have caused. The oral histories focused on three components of the participants' pathway to their advanced degree.

In order to address the research questions, there were seven steps to conduct the oral histories. First, the oral histories were broken into three interviews each per participant. Second, each of the three interviews was built around central themes of inquiry. For interview one, the general discussion focused on navigating early education, better understanding the subjects' family life, and learning about any traumas experienced. For interview two, the discussion centered around navigating high school and college (undergraduate). For interview three, the general discussion was about navigating graduate studies and career. To address the second research question, the third interview was also used to help explore the possibility of residual social-emotional effects participants experienced from the navigation and/or traumas suffered along the way. 
Third, the oral history interviews were conducted. The oral histories focused on three components of the subjects' pathway to their advanced degree. The oral history captured stories about their experiences growing up in poor communities impacted by the crack epidemic and any trauma the participants experienced as a result. The second theme focused on navigating educational challenges. The third theme focused on stories that captured their unresolved emotional scars resulting from navigating through their academic achievement or residual impacts.

Fourth, field notes and reflective data memos were used to help document interactions with participants and process the development of each of their stories. Field notes were also used to help recognize this researcher's positionality and power in relation to the narratives participants shared and the overall study. Field notes were maintained during the interviews with participants to collect the raw and authentic reactions of each participant and the reactions between the interviewer and interviewee. A total of nine interviews were conducted.

Fifth, all recorded interviews were sent off to be professionally transcribed. After the transcripts were returned, the data was then reviewed line by line. Sixth, the data analysis was conducted by referring to field notes to compare data line by line. Trusted colleagues and professors aided by assisting in reviewing existing literature and helping examine emerging concepts and themes. Finally, the findings were recorded for each participant individually as well as compared across the case studies for any themes or 
similarities between all three cases. This method of data collection and analysis was used for both research questions.

Table 3.1 Oral History Breakdown

\begin{tabular}{|l|l|l|l|}
\hline \multicolumn{3}{|c|}{ Central Themes of Inquiry } \\
\hline & $\begin{array}{l}\text { Interview 1: Early } \\
\text { Life; K-8 }\end{array}$ & $\begin{array}{l}\text { Interview 2: HS- } \\
\text { Undergraduate Studies }\end{array}$ & $\begin{array}{l}\text { Interview 3: Graduate } \\
\text { Studies, Career, } \\
\text { Residual Impacts }\end{array}$ \\
\hline Goals & $\begin{array}{l}\text { Understanding the } \\
\text { community and } \\
\text { general environment } \\
\text { you grew up in }\end{array}$ & $\begin{array}{l}\text { Navigating high school } \\
\text { and undergraduate } \\
\text { education experience }\end{array}$ & $\begin{array}{l}\text { Navigating grad school } \\
\text { experience and } \\
\text { professional life after } \\
\text { becoming doctors/lawyer }\end{array}$ \\
\hline $\begin{array}{l}\text { Navigating early } \\
\text { education (K-8) }\end{array}$ & $\begin{array}{l}\text { Understanding the } \\
\text { navigational strategies } \\
\text { and experiences of that } \\
\text { time }\end{array}$ & $\begin{array}{l}\text { Understanding the } \\
\text { navigational strategies } \\
\text { and experiences of that } \\
\text { time }\end{array}$ \\
\cline { 2 - 4 } & $\begin{array}{l}\text { Discussing any } \\
\text { traumas during that } \\
\text { time }\end{array}$ & $\begin{array}{l}\text { Understanding the } \\
\text { community and general } \\
\text { environments during } \\
\text { those experiences }\end{array}$ & $\begin{array}{l}\text { Understanding the } \\
\text { community and general } \\
\text { environments during } \\
\text { those experiences }\end{array}$ \\
\hline $\begin{array}{l}\text { Each participant participated in 3 separate interviews for an hour each. Each participant } \\
\text { conducted 3 hours of interviews }\end{array}$ \\
\hline $\begin{array}{l}\text { with a total of 9 hours across all participants. } \\
\text { Discussing any tri!lunas } \\
\text { during that time }\end{array}$ & $\begin{array}{l}\text { Discussing any residual } \\
\text { impacts from educational } \\
\text { journey }\end{array}$ \\
\hline
\end{tabular}

\section{Recruitment and Selection}

This study investigated the lived experiences of three Black males who successfully navigated unique sociocultural, emotional, economic, and political barriers 
such as overcoming poverty, abuse, and trauma to earn doctorate degrees. Therefore, all participants needed to fit particular criteria. Requirements for participation required those selected to (a) be a self-identified Black male, (b) born between the years 1975 and 1990; (c) have grown up in poverty, meaning they qualified for free lunch in school; and (d) attended an urban K-12 public school. These criteria were chosen to better understand how sociocultural, political, and environmental circumstances positively and negatively impacted on the lives of each participant. Below is a description of each criterion.

Purposive sampling to select the participants for this study. According to Purposive sampling is a non-probability sample selected based on characteristics of a population and the objective of the study (Tongco, 2007). Participants were selected through my personal network and professional social media networks. I am part of a social media group for Blacks that either have or are pursuing doctorate degrees. The group has a membership of more than 9,000 members. I posted the participation criteria in the group and responded to all that inquired. Between the multiple methods of finding participants, I chose one from my personal network, one came as a result of my extended academic network and the final participant came from my professional social media network. All three fit the criteria. The full profile of each participant is located below in Table 3.2. 
Table 3.2 Participant Profiles

\begin{tabular}{|c|c|c|c|}
\hline & Participant 1 & Participant 2 & Participant 3 \\
\hline Pseudonym & $\begin{array}{l}\text { Demarcus from } \\
\text { New York }\end{array}$ & $\begin{array}{l}\text { Donald from } \\
\text { Oakland }\end{array}$ & $\begin{array}{l}\text { Antwan from } \\
\text { Richmond }\end{array}$ \\
\hline $\begin{array}{l}\text { Location during } \\
\text { Childhood }\end{array}$ & Brooklyn, NY & Oakland, CA & Richmond, CA \\
\hline Year Born & 1982 & 1978 & 1975 \\
\hline Terminal Degree & JD & E.D. & Ph.D. \\
\hline $\begin{array}{l}\text { Major Boundaries } \\
\text { Encountered }\end{array}$ & $\begin{array}{l}\text { Had a parent } \\
\text { incarcerated }\end{array}$ & $\begin{array}{l}\text { Had a close friend } \\
\text { killed by violence } \\
\text { Transferred schools } \\
\text { more than twice in } \\
\text { an academic year } \\
\text { Father left. Raised } \\
\text { by step-parent }\end{array}$ & $\begin{array}{l}\text { Lived in a shelter } \\
\text { Had a parent } \\
\text { incarcerated } \\
\text { Had a close friend } \\
\text { killed by violence } \\
\text { Been incarcerated } \\
\text { Transferred schools } \\
\text { more than twice in an } \\
\text { academic year }\end{array}$ \\
\hline $\begin{array}{l}\text { Impact from } \\
\text { Crack Era (In the } \\
\text { words of the } \\
\text { participant } \\
\text { applying for the } \\
\text { study) }\end{array}$ & $\begin{array}{l}\text { Poverty, father } \\
\text { incarcerated }\end{array}$ & $\begin{array}{l}\text { Neighborhood } \\
\text { depleted. Family and } \\
\text { friends incarcerated }\end{array}$ & $\begin{array}{l}\text { Section } 8 \text { housing } \\
\text { No fathers around in a } \\
\text { positive way } \\
\text { Violence was a } \\
\text { constant } \\
\text { Mother abused }\end{array}$ \\
\hline $\begin{array}{l}\text { Signed Informed } \\
\text { Consent }\end{array}$ & Yes & Yes & Yes \\
\hline
\end{tabular}




\section{Profile Requirements for Subjects}

Each subject was required to be a Black male that lived during the crack epidemic and attended K-12 schools and higher education in the aftermath. Each subject had to be born between 1975 to 1990 . The significance of choosing Black males that grew up in the crack era is that they faced particularly daunting sociocultural, economic, educational, and political environments. As stated earlier, attending urban school in the late $1980 \mathrm{~s}$ and early 1990s as a Black male most likely meant living in poverty-stricken environments with little-to-no opportunity for social, emotional and economic growth. It also meant that Black males were being suspended, expelled, and disciplined at highly disproportionate rates that exacerbated the increase in incarcerations and Black homicides (Harris III \& Wood, 2013; Fryer, Heaton, Levitt, \& Murphy, 2013).

Each participant had indicate a history of growing up in poverty. This factor is significant because the implication here is that the family unit was in financial despair in some aspect which puts pressure on the microsystem and mesosystem (Bronfenbrenner, 1986). Participants self-identified as having grown up in poverty by answering the question, "Were you eligible for free lunch?" Free lunch in America is commensurate with what the federal government deems as poverty levels as it is based on the income of the parent(s).

Each participant was required to have spent significant time in urban, public K-12 schools. For this study, to qualify, the school must be $75 \%$ nonwhite students. Urban public schools were not performing well for Black males in the late 1980s and 1990s, 
much like they are not now (Lee, 2002). This information added value to the study to better understand what the immediate educational culture was for the participants. Participants were not disqualified if they split time in a private school (like Antwan) or a magnet school (Demarcus) as they each spent significant time in poverty-stricken urban public schools.

This study used special pseudonyms. The pseudonyms used in this study represent people from my childhood that were not as fortunate as our participants or myself. I wanted to honor their lives by using their names in this study. Demarcus was my friend in junior high. He was a big kid and often looked older than he was. In the summer between eighth and ninth-grade, Demarcus was murdered in front of his home. Donald was one of my best friends that lived a block away from me. He dropped out of school and sold drugs. After a few short stints in jail, he came home, had a daughter, and began to change his life for the better. Sadly, he was later shot in the head in his car. Finally, Antwan is my cousin. In between living in shelters, my family lived in the basement of my aunt's house where Antwan also lived. We grew up in North Oakland, California together. Antwan would have multiple stints in jail. The worst instance coming when he was trying to rob a gas station, and he ended up getting shot in the face. He survived and at the time of writing this, is back in prison.

Each pseudonym was chosen to honor childhood friends and family memories and to also show that not much separated these fallen Black men and the participants' who are now highly academically successful Black men. Small things accounted for huge 
differences in the lives of these six people. It also meant a lot to me to bring in the spirit of my friends that both supported me and helped raise me. By bringing in these very real people, I hope that readers understand that this research is not just to prove or disprove theories or live in a place of what-if. By incorporating and honoring in my deceased and struggling friends, it shows what happens when we fail so that we may better understand how to change our future.

\section{Oral History Interview Data Processing}

After the transcripts were transcribed, the transcripts were individually reviewed and small corrections were made whenever the transcribers may have misspelled or misunderstood slang or other idioms. Notes were written on general reactions of the researcher to each subject's stories. The transcripts were also shared directly with the participants.

Next the transcripts were organized by categorizing passages. The three categories were chosen as a result of Bronfenbrenner's Ecological Systems Theory described in chapter 2. By using Bronfenbrenner's model, we aimed to look both at the participants and the environmental impacts affecting the lives of each subject. The three categories in which passages were categorized were (1) trauma, (2) navigation strategies, and (3) residual impact. Each category term was given a definition.

Trauma is defined as an emotional wound or shock often having long-lasting effects (Webster's Dictionary, 2018). Navigation strategies are defined as skills and/or tactics used to help the student attain academic success. Residual impact is defined as any 
effects that remain for the subject for the trauma and/or navigation the subject experienced. 


\section{Chapter 4: Oral Histories}

This chapter explores the navigational strategies deployed by three highly academic successful Black men who have been impacted by the crack epidemic. The chapter focuses on the following research question: what educational and other navigational strategies do Black men impacted by the crack epidemic use to survive public education to achieve doctorates? In this chapter, this question is addressed by focusing on the individual skills each participant displayed. After the retellings of the oral history, the three case studies are compared to better understand the strategies that were utilized by each of these men. In Chapter 5, the first research question is addressed as a collective by looking at the potential ways the mutual strategies may be deployed by students, their families, and their educators. The second research question, what are the unanticipated social-emotional residual effects as a result of rigid academic achievement for Black boys? is addressed in Chapter 5.

These oral histories demonstrate the ways in which social and environmental factors influenced each of these men's life trajectory. It is important to note that throughout the oral history process, there was an overwhelming amount of data and stories. In choosing what to include, choices were made to highlight the stories that addressed the research questions most directly. The oral histories were retold in the following structure.

The first goal of the oral histories was to better understand the contextual factors that contributed to each of the men's life journey. Using Bronfenbrenner's social- 
ecological model each oral history revealed the ways in which each level of social context shaped their journey. The oral histories give context to their neighborhood, peer groups, families, and socio-historical conditions of the time -- which includes any of the traumas incurred as a result of that context. Second, the oral histories examine the experiences throughout the full spectrum of the schooling experience. This includes grade school through doctoral attainment. The oral histories discuss the strategies and tactics they used, or lack thereof, as they matriculated throughout their academic

careers. Finally, each oral history explored where each subject is today and whether there are any residual impacts from their life journeys.

\section{Demarcus, Brooklyn}

Demarcus was born in 1982 in Brooklyn, New York. He is a traditionally trained lawyer currently living in Arizona with his young growing family that consists of his wife and two children. He founded a small education nonprofii that works with underserved children. Demarcus has a calm demeanor and is a soft-spoken man. He speaks with intention and a level inflection. When he tells his story, he is rather even-keeled.

Like many Black men who have navigated the challenge of growing up in tough urban communities, Demarcus wears his success with a thin veneer of insecurity. The fractured relationship between him and his father served as both motivator and at times, a detriment to growth. He is still confronting that trauma today in some ways. Here are Demarcus's reflections of how a hyperactive Bajan kid from an immigrant family in Canarsie came to be on the fast track to partner at a powerful law firm. 


\section{Demarcus' Family Background}

In order to understand Demarcus, it is important to understand how his family reacted to the immigrant experience in Canarsie. His family is originally from Barbados with Demarcus being part of the first generation to be born on U.S. soil. His family was large with his mother being one of seven children and his father being one of four. The community he grew up in was an immigrant community with immigrant values, which we learned from Demarcus's testimony basically means putting your head down and working hard, understanding the opportunity the United States offers versus their homeland, and seizing the opportunities in front of them.

Both of Demarcus's maternal and paternal grandmothers came into the United States on work visas cleaning houses for years until they could get sponsored and begin sending for family members one by one. Once those members came over, they too would work for years to get sponsored until finally, a large portion of Demarcus's family was living in the New York/New Jersey area.

Similar to the other immigrant families living in Canarsie, their family lived in a one-bedroom unit with 8 family members. As immigrants in the New York 1980s, his family stuck to their Bajan roots. They looked at America as the land of opportunity that required sacrifices such as an overcrowded apartment. Family means a lot to the Bajan culture. In their immigrant community, you bought fish from the fish market, meat from the meat market, fruits and vegetables from the shop that sold fruits and vegetables and so forth. Many of the women would clean homes in upper class New Jersey for white 
folks. Outside of their family unit however, New York was changing rapidly. The crack epidemic would move into New York in what felt like an overnight thing and with it came extreme violence.

His family had a strong view of what America represented. It was a different kind of freedom. Even with the limited space and lack of money, they were fortunate, and his family lived these values. Their value system dictated that if they handled their business, success would come. Their family knew there would be tradeoffs for living in the land of opportunity and they could have more control over their future here versus Barbados. Living in America was a prize. So, when crack showed up and violence spiked, his family got even more stern.

Demarcus's parents divorced early in his life partly because of how different each of them was. Demarcus's mother worked hard to be responsible and set that example for her children. His mother was a bookkeeper early on and eventually went back to school for her CPA when Demarcus started high school forcing him to fend for himself more. Demarcus describes his mother as socially awkward and difficult to communicate with at times. Even in her awkwardness, she always pushed Demarcus to be self-sufficient and take advantage of all that the United States has to offer. Demarcus's mother provided a rich cultural experience for her children. Though she was poor, she prioritized the arts for her children through piano lessons and taking tours throughout different parts of New York to expose her children to different things. Demarcus's mother worked a lot of hours 
and made sure she put education first for Demarcus. She interacted with Demarcus very differently than his father.

Whereas Demarcus's mother is awkward around people, Demarcus's father is the social opposite. Demarcus's father has always been the popular guy and had a way with words. In Demarcus's eyes, he took irresponsible risks and was often not dependable. Demarcus's father was a hustler and oscillated between legal and illegal ways of getting money. One of his father's jobs was selling SAABs in New Jersey when Demarcus's mother was pregnant with him. He was making a six-figure salary but squandered the job away when he got into a disagreement with his boss and verbally berated him. He was fired and added extra stress to the family. The couple would eventually break up.

After the divorce, Demarcus's father moved to Miami after the break-up and set new roots. He found another woman who would become Demarcus's stepmom and mother to Demarcus's little brother, also named Demarcus. One time, on a visit to see their father in Miami, Demarcus's sister was playing in her father's room and found a stack of cash and a gun to which Demarcus's father's reply was, "Don't tell your mom."

Demarcus's father was flashy and liked to live above his means. He could never hold onto money. One of Demarcus's father's best investment and his most pronounced legal job was when he ran a nightclub in South Carolina and would commute from Miami. The club would host many legendary rappers that were on the come up in the nineties such as the Notorious B.I.G., Snoop, and the 'Ol Dirty Bastard. The club was successful but his father constantly made poor decisions with money and his time, and as 
a result, he eventually loss the club and began moving drugs which would eventually land him a bid in prison.

By 1989, crack cocaine had saturated Black neighborhoods with damning results. Research estimates cocaine arrests, homicides, and violent crimes had all spiked and reached its apex across the country in Black neighborhoods, including New York (Fryer, Heaton, Levitt, \& Murphy, 2013). In 1988, New York City spent $\$ 500$ Million on drugrelated enforcement. Crack played a role in $38 \%$ of the 1,867 murders in the city. Crack cocaine contributed to cases in which parents under the influence of drugs abused or neglected their children with growth from 2,627 cases in 1986 to 8,521 cases in 1988 . New York's jail population grew from 9,815 in 1985 to more than 17,500 by February 1989. The jail population in New York City grew so much that it was declared a "jail emergency" due to overcrowding. In 1988, Brooklyn alone, which is where Canarsie is located, had 83,000 arrests, which was up from roughly 70,000 just three years prior (Marriott, 1989). In all of these cases, Black people were disproportionately impacted (Fryer, Heaton, Levitt, \& Murphy, 2013). The violence was heightened and everyone in Demarcus's family braced for it,

So, that was a reality...we lived in one of the upstairs units, and I remember when I was in middle school, I know there was always something sketchy going on downstairs, but the guy downstairs just got shot dead in front of our building. I heard the bang while I was sleeping, I said, "Now that's a weird noise, maybe one of the speakers blew out," because they were always having these loud parties. 
Demarcus did not recall any sit-down discussions, just hyper focus by Demarcus's family unit on minding their business. Just go to school, do after-school activities, come inside. From Demarcus's recollection, the neighborhood seemed to change overnight, he describes, "When I got off the subway station you would constantly see crack vials all over. And it was so interesting the way that all worked. It was like one day, all that crack was [just] there." Demarcus remembers not being able to buy chips at his corner store anymore because his grandmother was convinced it was a drug front. His family told him to stay far away from the drug dealers and the bodegas throughout his community.

Even though crack hit his community hard, he felt that his town withstood it well compared to other Black communities throughout the country as the community even now is still intact with the lineage that lived there during Demarcus's childhood in the eighties and nineties. Demarcus credits much of his neighborhood remaining together even today to their immigrant values. Even with the heightened crack use and rise of violence, Demarcus's family, much like the other immigrant families in the neighborhood, viewed the United States as a dream come true. His family truly subscribed to the belief of the American Dream, that if they kept their heads down and worked hard, they could build the type of life they wanted.

It was like one day, all that crack was there, and then one day it wasn't. At some point, it just stopped. I don't know how that actually happened, but growing up, middle school, and at least until high school, the crack stuff was real. And I would 
say we had a strong community that most people on my block, have never left.

And I'm talking people my age with their own kids, they still live on the block. It is important to note that Anthropologist John Ogbu has also found the same trend with American immigrants. His 1995 study found that American immigrant students embraced an "upward mobility culture" which came in the form of working hard and focusing on the task at hand (Ogbu, 1995). Demarcus's mother exemplified this by doing her best to isolate him from the discord that crack in the neighborhood created, emphasizing education above all, and exposing him to what she felt was upward mobility culture through the arts.

\section{Demarcus' Navigation Strategies}

Despite the devastating impact crack cocaine had on Brooklyn as a whole, Demarcus and his family deployed several navigation strategies both knowingly and unknowingly. The strategies they deployed, sometimes with the help of others, included (a) proximity to success, (b) replacing the father figure in Demarcus' life, (c) utilizing the navigational capital of caring adults within the school building, (d) bussing Demarcus to better schools outside his neighborhood, and (e) taking full advantage of extracurricular activities and exposure to the larger artistic culture New York had to offer.

\section{Strategy 1: Proximity to success.}

As a young kid, Demarcus spent significant time getting a vision of successful people and circumstances. From his mother showing him everything New York had to offer to spending time at a friend's home where both parents were highly successful. 
Demarcus's proximity to traditional success offered him a model early on to strive for in adulthood.

Demarcus's mother made sure she spent a significant amount of time with Demarcus and his sister exploring the New York cultural scene.

The reason I bring up the stories about doing piano and all these things is because that was my weekends. My summers were typically some sort of enrichment ... because my mother was probably of the belief, rightfully so, that idle time is the devil's time. So, whether it was camps at the church got put up, random free stuff she would ... my mother was an expert navigator. Even more so than my other aunts and uncles. My mom was one of seven. And she was lowest income out of everybody. She was the only one raising kids by herself. We're the only ones that had any one of our parents get caught up in the system.

Demarcus's mom worked a lot, but she always made time to take them around the city and show them the sites whether they be the Statue of Liberty or a museum. Demarcus credits his mother's ingenuity because they were very poor, but she found ways to expose them to culture for cheap or free.

But, I think that kinda forced her to be innovative. We had these New York City summer vacations, where she just would take us to the Statue of Liberty, and on the ferry, and do all these things that were not expensive, and didn't require a hotel or anything like that, but our exposure to museums and culture, and we might not have seen Broadway shows at that point, but we would see free shows 
at Lincoln Park, or free shows, and summer showcases, and other street fairs. I mean, she was super savvy with it.

Demarcus gleamed as he discusses his mother's ability to navigate and expose his family to culture in the face of poverty. He sat back in his chair and sort of marveled at her strength as he retold this part almost as if he was appreciating it all over again. Being exposed to a variety of the arts and cultural experiences made the concept less foreign to him and would serve him as he reached for success later in life. Demarcus explained that this type of enrichment made him feel like he was worthy and deserving of great things and that feeling has never left him.

Demarcus does make mention of the impact his father leaving had on him. His voice changes slightly. Demarcus grows a little more animated as he tells this antidote, I think about my upbringing like I don't know how to throw. Now I don't know that him being around would have taught me how to throw, but I just don't know how to throw. I really don't know how to fight. Again, I don't know that that's something that dads do, like I'm probably not gonna teach my son how to fight because I don't really know how to fight. But growing up without a dad, was one of those things where even as a grown man before I had kids, I would see a kid playing with his dad and feel sad. [I would] be like, "Man, I missed this. I never had this." I had a lot of other male mentors that played different roles but there's nothing like having a father. And there's nothing like being completely abandoned by your father. 
Even with the pain and Demarcus's mother kept Demarcus in close proximity to success. She kept him and his sister in the arts scene in New York, so they constantly saw people living out their dreams. When it came time for Demarcus to follow his dreams, the concept was not foreign to him and it paid off in the long run.

\section{Strategy 2: Utilizing father figures even if the biological father is absent.}

Demarcus's father being gone left a void and it showed in his behavior. In elementary school, he had behavior issues and a lack of discipline. Demarcus's mother filled that void with her relatives and neighbors to ensure Demarcus had positive male energy around him which included his uncles and one of his friends' father who would eventually represent Demarcus's mother in court.

Demarcus's uncles stepped in to help provide the discipline. Demarcus, being only in the first grade at the time, recalls really liking having his uncles around stating, ...like anything else when you talk about poverty, when you're in it, you don't even realize it. When my parents first split up, I lived in a one-bedroom apartment with at least eight people in there at a time. Sometimes more. And if you look at that as an outsider, man that sounds really rough. But as a first-grader it was lit. It was great. I had all these people all the time to talk to. We were always playing games. I was involved in these arguments and stuff all the time. I was hearing relatives arguing about politics and stuff like that and sports and boxing all the time. 
This passage exemplifies that extended family played a significant role in Demarcus's journey. Listening to politics and living in a one-bedroom apartment provided Demarcus with a situation that forced him to constantly be in community. In addition to helping with the discipline, Demarcus credits his uncles with helping him develop his vocabulary and critical thinking skills early on because he had to have conversations and argue points. His uncles helped carry the load as Demarcus's mother had to work a lot just to provide. He did not know he was poor or that that many people in one home was not normal, he just felt loved. He got a better view of a more prototypical family in the form of his mother's family court attorney.

Demarcus had a friend whose father was a successful lawyer and his wife ran a travel agency. Their home was a traditionally successful home, meaning his family had dinners together, did family outings and had a general structure of what a father did and how he provided. Demarcus explains, "[I got a] lens into a different sort of life, and what that kind of hard work academically can do. It definitely instilled a lot of values in me. [My friend's] dad was very much a very prominent father figure for me." His experience with this family played a major role in Demarcus's own decision to become an attorney. Although Demarcus's uncles and his friend's father played huge roles in his development outside the school, Demarcus and his mother would still come to depend on the knowledge of caring adult allies working inside the school building to ensure Demarcus got the best shot possible at getting a good education. 


\section{Strategy 3: Bussing Demarcus to better schools.}

Demarcus's mother took Demarcus out of his neighborhood school and sent him to schools that fit his needs better and had better academic results with children. In elementary school with the help of a school staff member, Demarcus's mother learned that Demarcus would be better served at a school on the other side of town.

So that was kind of what my elementary school experience was like at that point. It was transformational. Be a part of this gifted program where I was essentially double accelerated in every subject, and just always pushed, always intellectually challenged, to the point where, I didn't even realize that what I was doing wasn't even normal. It was just this normal environment that we were in, and we just were pushed. I can't even explain it any other way.

Once his mother saw the drastic difference in how Demarcus was treated once the switch happened, she would continue to choose his schools based on their performance rather than what was in their neighborhood. She chose his elementary school, his middle school and high school. Although Demarcus did not always like it [in strategy four there is a discussion about him rebelling in high school because it was predominantly Asian], his mother had no problem taking him out of his neighborhood school if it meant he would get more elsewhere.

And, when I did the test, my IQ scores were at whatever level, so I ended up going to a different school than my sister was going to, and I would take ... a van would come pick me up in the morning and take me to this school. And I 
remember when I first started, I was like, what in the world are we doing here? I started like maybe a few weeks into my second-grade year. And they started their days with creative writing. We just would write based off what topic was on the board. And I remember we would illustrate our own fairy tales and write our own fairy tales. I never got bored.

Demarcus's mother wanted to ensure that her son was getting the most out of whatever school she sent him too. In this instance, Demarcus went from having physical outbursts that he could be suspended for to having his energy channeled into enrichment programs that brought the best out of him.

And the same kinda behavior I used to get in trouble for, was now what was encouraged. Now we talked all the time. Now we were supposed to work in groups. [I]n my [old] elementary school we had about 30 kids in every class. My gifted classroom, we had 24. But what made that even stranger was, although 24 kids in my class, it was a bridged class. It was second and third grade, third and fourth grade, fourth and fifth grade, so that meant that, in this school, you have 30 kids per grade level, but you're only identifying 12 for this gifted program. In addition to the academics, Demarcus's mother wanted him to not lose the values of their people. Academic attainment and knowing your culture are not mutually exclusive, even if you attend a school that does not properly represent your culture. Demarcus's mom did the best job she could early on to ensure that he was also around 
other Caribbean Island immigrant children so they could reinforce the type of community practices she used at home,

And it's one of those things where you're like, all these immigrants, we had a lot of Haitians who didn't speak English as their first language, it was ... if talent is distributed equally, which I believe it is, why isn't the opportunity distributed equally? It was really kind of embarrassing looking back at it, that only 12 of us

per grade level were selected for this, because there was so much other talent that was out there that doesn't get recognized because of those other sorts of filters.

Although Demarcus's mother was not wealthy, she did do her best to take advantage of the educational options offered to her for her children. She would continue this practice in both middle school and high school. It is important to note that she did not naturally possess the navigational skills to choose a variety of schools for Demarcus, so she often got help from within the school building.

Strategy 4: Utilizing caring adults inside the school building.

Throughout his educational experience, Demarcus was fortunate to find effective caring adults. Each caring adult came into Demarcus's life at distinct periods of his educational journey when Demarcus could have faced harsh consequences that could have completely interrupted his eventual academic success. The three were (a) Ms. Robinson in elementary school, (b) Ms. Simon in high school, and (c) Ms. Urtz in college. 
As mentioned earlier, when Demarcus's father left, Demarcus's behavior became aggressive at school. In the first grade, Demarcus was hyperactive. Demarcus grew belligerent and could not sit still. Once during reading time, Demarcus slapped the book out of his teacher's hand. He was in trouble weekly, and his mother grew frustrated. She just didn't know what to do with Demarcus and his energy. Enter Ms. Robinson, [A] Black woman named Ms. Robinson, told my mom that I needed to get tested. And I think my mother probably assumed that something was wrong with me, but she was like, you actually need to test him for gifted and talented program because it wasn't offered in this district, but if he got tested, then maybe he might be able to be bused to a different school in another district. And, when I did the test, my IQ scores were at [high], so I ended up going to a different school than my sister was going to, and I [took] a van [that] would come pick me up in the morning and take me to this school.

Demarcus did not explain how Miss Robinson knew he might be gifted nor did he know exactly why she felt so inclined to intervene. However, the new school was a better choice for Demarcus and ultimately put him on an improved path as his schooling experience was much different now,

I started like maybe a few weeks into my second-grade year and they started their days with creative writing. We just would write based off what topic was on the board and I remember we would illustrate ... and write our own fairy tales. I never 
got bored. And the same kinda behavior I used to get in trouble for, was now what was encouraged.

Ms. Robinson helped Demarcus escape a school that wanted to suspend him for his energetic and creative behaviors to a school where those things became assets. He stayed in this type of environment for a while, but things would shift once Demarcus got to high school.

Ms. Simon would be the loving adult inside the school building helping Demarcus in high school. In high school, Demarcus did not like the fact that most of his classmates were Asian. Up until this point, he was always around Afro-Caribbean students that he could relate to on a cultural level. The Asian students spoke differently, they studied differently, and to Demarcus, they felt inauthentic.

As a result, Demarcus rebelled because if he started acting like the other students and mimicked their tactics, it would have felt "corny" or as Ford, Grantham, \& Whiting might describe it, someone who has betrayed his race and adopted the values and tactics of the enemy (2008). So, Demarcus chose to resist that feeling and started habitually skipping school. Demarcus missed so many days of school that the he was almost expelled. After racking up more than 80 cuts he had a sit down with his counselor, Ms. Simon.

Ms. Simon was an older Jewish woman, a "seen it all, done it all" type that would make crass puns that Demarcus compared to the ones Jerry Orbach would make on Law and Order. Demarcus did not know Ms. Simon well. The first time he actually met her 
was when she called him into her office to discuss his cuts and failing grades. Ms. Simon did something that many adults up until this point had not with Demarcus, — she held him accountable. Instead of just allowing Demarcus to fail, Ms. Simon gave Demarcus the option to improve his attendance and check in with her weekly. Demarcus had to take an attendance sheet to every class and turn it in to the counselor.

The support from his counselor made a huge difference and it showed in Demarcus's performance. He explains,

It might have been an interesting form of reverse psychology, but it felt like the first time in a long time I ever had a choice. My mom made me go to this other school... [But after having a choice] something flipped... I went to summer school and made up the classes I failed."

Through this process he gained new confidence and improved his relationships with his teachers.

Ms. Simon used her positional power to give Demarcus a chance to excel in a situation that by all accounts should have ended up being punitive. Instead, Demarcus was able to finish high school in such a strong manner that he applied and was accepted into competitive universities, including Syracuse, the school of his choice.

In college, Ms. Urtz would be there for Demarcus when he needed someone most. Demarcus got into his top choice for college, Syracuse. He quickly excelled there quickly both socially and academically. He was an involved student on campus which eventually 
led to becoming part of student government. As a member of student government, he was now a decision maker on campus.

In the context of the time period in New York, an ardent supporter of the broken windows theory, Rudy Giuliani was attempting to follow through on his promise to lower crime through policies such as Stop and Frisk. As a young activist, Demarcus spoke out when Syracuse wanted to host the mayor. Taking on the popular mayor led to a year of turmoil and trauma for Demarcus that would've cost him his college enrollment until another caring adult intervened.

Demarcus loves being a Syracuse graduate. When discussing the school, his voice lights up as he remembers his time at the university. The pride radiates through him until he relives the moments leading up to what was almost his dismissal from the school. Demarcus describes what was going on in New York and the broader country during this time.

It was 2001, and the terrorist attacks on the Twin Towers in New York had just occurred. Giuliani was mayor, and he made a promise to clean up the New York crime scene and make the city feel safe again by utilizing the broken window theory. The broken window theory stipulates that by lowering the visibility of smaller, petty crimes such as loitering, vandalism, and fare dodgers, you create an atmosphere of lawfulness that ultimately lowers the crime rate. These policies included 'Stop and Frisk", an invasive procedure that allowed police officers 'to practice of temporarily detaining, questioning, and at times searching civilians on the street for weapons and other 
contraband' (New York State, 2013). This translated into Black and Brown men being disproportionately harassed by police. Giuliani was named Time's Man of Year during this time. Giuliani was on a mission that would ultimately impact Demarcus in a very significant way.

At the same time, Demarcus was an active member of student government on campus. Syracuse invited the "Time's Man of the Year" to come speak there and Demarcus spoke out against it in a very public way, When Giuliani was doing his whole cleaning up the streets thing, he's doing it on the backs of people that look like [me]. These are people that are being stopped and frisked for no reason as part of their policy of cleaning up the streets. I remember feeling deeply troubled by it...I got a petition of 700 students and I said "...This is certainly of interest, and it has personal interest to me." I didn't really know what I was in for when I challenged America's mayor and decided to say ... "Giuliani was Time Man of the Year, whatever, so was Hitler. Moving on." ... You don't compare anybody to Hitler, especially in New York. Everything hit the fan after that!

The Hitler-line took Demarcus to a new level of public attention; he was featured on Fox News and other major outlets, he received death threats, and his grades struggled to a point where his enrollment was threatened. Due to Demarcus's drastic drop in his GPA, his financial aid was in jeopardy and he was not making much progress with the financial aid office on his own. 
Then the Dean of Students, Ms. Urtz, stepped in on his behalf. Ms. Urtz was a Black woman on campus sympathetic to Demarcus and his bravery for standing up to power the way he did. She noticed how much of the white faculty lacked support for Demarcus or the other students of color standing together in protest. When Ms. Urtz stepped up, she also recruited other members of the faculty. Ms. Urtz knew how to navigate the financial aid system and made an appeal on Demarcus' behalf. Ms. Urtz intervened when she did not have to and utilized her social capital in a way that spared Demarcus's college career.

\section{Residual Impact}

By most accounts, Demarcus's academic success is pronounced. He was able to attend some amazing public schools that piqued his creativity, he graduated high school at the top of his class, and he went to his top college prospect and made an impact there. From there, he was chosen to be part of Teach for America, which has a very low acceptance rate. Then he went on to a top law program and was working on the fast track to one day becoming partner at a large firm. On the flip side, his young growing family felt abandoned and he ultimately was not happy. Even at the time of this report, you can hear the pain in his voice.

Demarcus picks up his story shortly after law school. He sat back in his chair and took a breath before he discussed his wife and just how influential she was in his life. I heard the love and admiration in his voice when he discussed why he is so fortunate to have his wife in his life. "Some people say they want a ride or die chick. I want a GPS 
chick. I don't want to die. I want someone that's going to help see the way and really help me see myself. She was with it!" With his wife, Demarcus found a type of love that he did not know existed. She was the motivating force that led him to get his law degree. Her support helped Demarcus graduate from Law School at the top of his class. She encouraged him to purue his dreams even as they had a young child and were working on a second. Even with all this support, Demarcus was so blinded by his own early traumas that he was three months away from this amazing woman packing up and leaving him.

Demarcus almost missed the signs that his wife was sending him. Judging from even how he was telling the story, he was and to some degree, still is, working to be a better provider, husband, and father than his own. Nearly every time Demarcus had to discuss his father, his demeanor changed. He was no longer as comfortable in his seat. His voice and tone grew dismissive. There was one instance in which Demarcus was retelling a story that involved his father and he interrupted himself midway through by simply stating, “[My father is] trifling, man, like a trifling dude. I don't know. I don't know how else to put it." Witnessing this internal exchange in present day makes it easier to understand how he almost missed the signs that his wife was unhappy because of how determined Demarcus is to not repeat any of his father's actions. That is the residual trauma still impacting Demarcus. Aside from with his wife, the residual trauma has impacted Demarcus in other ways too.

Due to his complicated relationship with his parents, Demarcus has always had a complicated relationship with other adults, especially the women in his life. He had no 
relationships longer than six months until he met his wife. Part of his unwillingness to truly engage in intimate relationships may be due to his complicated relationship with his parents. For instance, even though his mother did everything in her power to ensure he had the best educational opportunities, Demarcus often describes her as 'socially awkward'. His mother was supportive, yet stern. He had a revelation after graduating from Law School and his mother sent regards,

I remember I got this card and I started bawling hysterically. My wife was like, "What's wrong with you?" I was like, "My mom says she's proud of me." First time ever that I can remember her ever actually saying [the word] proud. Demarcus was surprised at the sudden rush of emotion he received after hearing his mother say that. However, even more provoking is the residual impact that his father has and continues to have on him.

Demarcus's disdain for his father is a result of this parent's abandonment, constantly cheating on his mother, a lack of responsibility, and being a convicted criminal. He sabotaged his jobs and was not able to be supportive financially. Demarcus's father brought his criminal activities home with him as Demarcus's sister stumbled upon drugs and a gun on one of their visits to their father's home. All of this led to a strong resentment that Demarcus still feels.

Demarcus worked so hard to not be like his father that he overcorrected and negatively impacted his own family almost resulting in his wife leaving him. Demarcus always wanted to make sure he provided financially and as a result, he always worked 
overtime at the law firm, even when his wife was pregnant. Demarcus did not actually enjoy being a lawyer, but in his mind, he had to be financially stable and support his wife better than his father supported his mother. He equated professional success with intimacy and genuine love but had to learn that they were not equal. Demarcus was close to reaching his professional goals. In his estimation, he was about a year away from a major milestone; however, that year may have proved fatal for his marriage, Demarcus reflects,

I don't think my marriage would have lasted another year. [My wife told me], "Yeah, more like three months." So, it was real. It was coming to a point where stuff was about to fall apart. And again, if I would have just focused on nothing but like my individual success ... and it was so weird.

Up until that point, Demarcus never confronted his issues with his parents in a positive way and as a result, doubt and anxiety guided his decisions. In his mind, Demarcus was doing what he thought a husband should do but was creating his own toxic situation for his wife and children.

Demarcus broke the behavior just in time and with the support of his wife, changed careers completely. He built a nonprofit that utilizes both his teaching ability and his knowledge of the law to build critical thinking skills in students across the country. He remembers his struggles in school and the hidden genius students possess. He remembers how he got lucky in school and was able to get into a gifted class while other 
students did not. Now, through his program, he works to pull the best out of his students through innovative ways.

The crack epidemic had a huge impact on New York as a whole, yet Demarcus's family structure worked hard to insulate him from the worst parts of it. So, while he saw the violence and the impact, his mother doubled down on their values of family, and she exposed him to the arts which are still a part of Demarcus now.

Demarcus is still personally reconciling the early traumas he has experienced, but he is now consciously aware of the need for healing and growth, so he can be the father and husband he wants to be. Although Demarcus was successful academically, no real healing took place along the way and in his quest to be better than his father, he committed his own mistakes that could have broken up his family.

\section{Key Takeaways from Demarcus's Story: Straight Outta Canarsie}

Today, Demarcus is a national thought leader who teaches students across the country how to develop and utilize their critical thinking skills. Demarcus has excelled in life as a student, teacher, lawyer, and now as a social entrepreneur. It took what amounts to divine intervention for Demarcus to not be punished and criminalized for just existing as a young Black boy in school. It is only imaginable what could have occurred if the early trend of suspensions and early over-medicating would have grabbed hold of Demarcus. Couple that with the early trauma he faced as a result of his father and Demarcus's story may have turned out quite differently. One should not have to be both brilliant and lucky to be successful. 
Although Demarcus grew up amid violence and poverty in Canarsie, his mother utilized everything at her disposal to keep him focused. She still needed help though. Father figures are important in the development of young Black men. Demarcus's case shows that the figure does not have to be the biological father. For Demarcus, his father figures were his male family members and his friend's father, who was a lawyer. Demarcus's mother supported the facilitation of those relationships.

Demarcus's brilliance was almost ignored and discarded. Had Demarcus not had Ms. Robinson, the chances are strong that he would have been suspended and potentially misdiagnosed and placed in special education. It took someone that looked like Demarcus to step beyond protocol and take a professional risk by telling Demarcus's mother to have him tested for being gifted. In Demarcus's case, Ms. Robinson arguably broke the rules to ensure Demarcus wasn't castigated to expulsion or a special education class he did not require.

Finally, the fractured relationship with his father was never truly resolved and it crept back up in ways that could have had dire consequences for Demarcus. The irony of Demarcus's story is the more he tried to not be like his father, the closer he got to almost having the same results which is being separated from his family. In every sense of the term, Demarcus was gritty. He put his emotions and anger for his father aside and focused on the larger picture. The lack or inability to deal with the issues he had with his father came back at the worst time, as trauma often does. From looking at Demarcus's 
case, Black boys are not taught to heal or manage pain in a meaningful way which can harm them in the present, and in Demarcus's case, the future as well.

\section{Donald, East Oakland}

Donald was born in 1978 in Oakland, California. Donald is the director of a nonprofit focused on Workforce development. He is also an education advocate and researcher focused on improving education for children. He has a doctorate in Educational Leadership and recently ran for the board of education in the neighborhood he currently lives in. Donald is a busy man. Donald works with felons reentering the workforce. As I waited in the lobby for our interview to start, I watched men eager to restart their lives comes into the space with visible stress on their faces. There was an angst and uncertainty in the room. So, when we sat down to conduct his first interview at his office, Donald was often interrupted. Each time he handled the inconvenience with a balance of care and resolve. The respect level for him is palpable at his office both from staff and those receiving aide. He rebuffed each interruption with reaffirming smiles and redirection. His affect seemed to calm otherwise tense employees. One man came in frantic but left calm, with whatever worry he had melted away. This is Donald in a nutshell, the calm during storm. Donald's story takes us through the life of a kid from a rough part of town that often feels like an outcast to a man struggling to define himself in the midst of his reality.

His family is from an East Oakland neighborhood in the flatlands, better known as Dag. As a child, Donald thought Dag stood for Dangerous Ass Gangstas, however he 
learned that it was the nickname came from an elementary school originally named after Nobel Prize winner, Dag Hammarskjöld. The neighborhood affectionately became known as Dag. Dag has been known for its high propensity of crime and drugs in the 1970s through today. Donald confirms that the amount of crime was high and rose during the late eighties and early nineties at the height of the crack epidemic.

Crack hit East Oakland hard in the late eighties. From 1980-90, Oakland experienced a $2200 \%$ increase in the amount of drug related cases. It is estimated that there were roughly 36,000 drug users in 1990 in Oakland. 40 percent of which were women. Of the women that gave birth during this period, 30 percent of the babies born had been exposed to drugs. $70 \%$ of the emergency room cases at Oakland's county hospital, Highland, involved acts of violence that were in some way drug-related. The influx of crack cocaine affected $70 \%$ of the Oakland students in grades seven to 12 in some way (Sutton \& Baker, 1990).

Donald recalls seeing kids as young as 11 years old selling drugs. Donald personally experienced the rise in violence and remembers that there were rules that emerged as a result. There was a sort of code established during the late eighties and early nineties. Donald explains the dynamic in his neighborhood:

[O]ur street was the street where a lot of people lived and a lot of people's grandparents lived. Back during that time, there was this thing called respect. I say this thing because I don't know that that exists anymore. You didn't do things to people's parents. You didn't do things to people's grandparents. You didn't do 
things to pregnant women. Right? When I say do things, beating people up, selling dope to them, doing that kind of stuff. That didn't happen in our neighborhood at least. If you broke into somebody's house and it was an elderly person and they didn't have anybody there young, something happened. There was a response. Typically, you'd get your ass beat and you'd be forced to replace whatever it is you stole.

Even in the midst of rising crime and drug use, there was a code of ethics that still had to be followed. The code did not prevent people smoking crack outside in the open though nor did it prevent middle school kids from selling crack and toting pistols. Donald has since moved from Dag but his mother and step-father still live there and the community, for better or worse, is still very much with Donald today.

\section{Donald's Family Background}

Donald comes from a large mixed family. Donald is the result of an affair as his biological father already had another family. He was never really involved in Donald's life. Donald was raised by his mother and his step-father. He is one of nine children. Donald has six brothers and two sisters. His mother was married young at age 19 and had two children from that marriage. Donald's mother divorced her first husband. Then she

met Donald's father and they had Donald. However, Donald was the product of an affair as Donald's father has two other children outside of Donald's mother. Donald's father was never present as he was already married. Then Donald's mother met another man whom she married. Donald's step-father already had two children from a previous 
relationship. Together, Donald's now step-father and Donald's mother had two more children.

Donald recalls growing up quite poor, "We were on welfare most of my life. But it was interesting because growing up, we didn't know we were poor because everybody around us was poor. We thought we were normal. I was the dirty kid in the neighborhood." At the time, Donald had no concept of poverty because everyone in his neighborhood was also poor. He referred to himself as the 'dirty kid' because he used to play outside with no shoes on. His naivete around poverty soon dissipated as he entered school and saw that he did not have the shoes or clothes some of the other kids had.

But it was interesting because growing up we didn't know we were poor because everybody around us was poor. We thought we were normal. I was the dirty kid in the neighborhood. I used to run around the streets with no shoes on and no shirt on because I enjoyed it. This is up until I was six or seven, so it wasn't like I was in high school running around with no shoes and so. Early on, I was the dirty kid on our street. My mom, although we had a house, we were renting from my grandfather, so the rent was probably really low.

Donald's use of the word 'normal' exemplifies the isolation poorer Black communities in Oakland lived in. Poverty was so rampant that it was normal and what came with living in that type of poverty was a culture that was also normal to those living in it. According to the 1990 Bay Area Census, Oakland was majority Black with a population of $43.9 \%$ and the below poverty rate was $18.5 \%$, which neighborhoods such as Dag fall into 
(2018). Normalcy, in this case does not change until it is compared to whiteness, which was seen as middle class. However, living in the normalcy of whiteness is of no value in the community and time in history in which Donald and his family were raised.

When Donald discussed his mother in the interview sessions, he was very intentional about giving her the benefit of the doubt. It was clear in his voice inflections that he had some resentment, but he wanted to be fair to his mother. Donald's mother is a true representation of being a product of her environment. She was the daughter of a pastor, so when she got pregnant at age 19, she became the black sheep of the family. She was on her own, and the strength she went on to build exemplified what many felt was needed in order to survive and keep her home together. Just like the neighborhood, Donald's mother followed a code. The code being that you were tough and showed no weaknesses to those around you. If people saw that you were afraid, they would take advantage of you. Donald's mother instilled this in her children. Elijah Anderson discusses this phenomenon in his 1994 Atlantic article where he stated, "[E]ven though families with a decency orientation are usually opposed to the values of the code, they often reluctantly encourage their children's familiarity with it to enable them to negotiate the inner-city environment." This understanding for the necessity of respecting the "code" is what allows Donald to honor and respect the way his mother raised him.

Education was not seen as a viable means to leave the hood. This is a time where Black males got clear messages that they either sell drugs or play sports. Survival was key. So when Donald was invited to get tested for the Gifted and Talented Program in the 
second grade, his mother would not allow it for fear that it would make him a target for bullies.

Donald's mom wanted to ensure she protected her children and she knew that if they were not respected in the neighborhood, they would be victims to bullying. An example of this in action was one day when Donald's brother loss a fight outside and came home crying, Donald's mom had a stern reaction,

[My brother] came in and he either had a black eye or he got beat up. He came home, my mom beat his ass, she gave him a whooping, she spanked him all right and said, "Okay well don't come back in this house until you win". He had to go out, he just lost a fight, went back outside and had to fight. He loss the second time. He had to go back outside and fight the kid again. Imagine psychologically what that does to you. My mom wasn't doing it to punish. What she thought she was doing was preparing him for the world right because if you get knocked down [you get back up].

That is Donald's mother and some of the complicated feelings he has in regard to her. In his eyes, things were tough but between his mother and her code, they helped prepare him for life.

\section{Early trauma.}

Donald experienced a lot early on in his life. Growing up in Dag, he saw a ton of violence regularly, had to always be ready to fight, would eventually lose his best friend to gun violence, and then had his own family and community mock him for his academic 
endeavors. These traumas played a major role in shaping Donald's view of the world. After understanding Donald's circumstances, he then shared his strategies used to obtain his academic success.

Donald discussed the feelings of his father leaving early. He was confused as to why his father left him and his family. He remembers seeing the neighbor's father in his home and would question why his father did not love him. When his step-father moved in, they never quite hit it off. Donald felt that his step-father treated him differently because he was not his biological son. Donald tried to build a relationship a few times, but when the stepfather failed to follow through on his commitments, Donald gave up. Donald essentially felt alone and consequentially dealt with his issues alone.

One issue he dealt with in the sixth grade was when he and his friend had a gun pulled on them. Donald recalls,

The first time I had a gun pulled on me, I think I was the sixth grade, and it was over. I don't know if they were joking. I didn't take the time to ask. I'm walking to school. Like I said, I grew up in Dag. One of them said, "Hey, blood, where you from?" I can't remember what I said. He said, "Oh, you think you're tough?" [There was an eighth-grader with me.] He [was] standing there with me. [The guy with the gun] was like, "Oh, you tough?" He was like, "Pop the trunk on this fool." One of them got out of his car, popped the trunk, pulled out a shotgun. That's the last thing I saw because I dipped [translation: ran]. 
Donald and his friend ran and got away. They were terrified but when they got to school and told the story, they got praise.

The violence was constant. There was another situation where Donald was on the bus,

There were a lot of instances of violence on the bus. In this instance, there were some boys on the bus, and one of them pulled out a pistol and brandished it. The girls in the back of the bus reacted frightened and he put it back in his waistband. At the same time, the boy [with the gun] saw a [random] slim white kid watching him, and the group of boys just beat [the white boy] and then threw him off the bus.

That was the type of aimless violence Donald was dealing with. There was often no obvious reasons for the violence, so Donald just had to remain on high alert all the time and the same was true for his peers.

It is a little easier to remain on high alert when you have a best friend and you do everything together. Tracy was Donald's best friend and they were always on those busses and in the streets together. So if anything did happen, at least there was someone else with Donald. In high school, Tracy was gunned down. Tracy and Donald had always looked out for each other. So when his best friend was murdered, once again, Donald was alone again in the world. Donald explained how he processed the death of his best friend, "These are just big events. My dad left and then Tracy got killed. What I ended up doing is filtering out people, I developed this 'fuck it' attitude." Donald effectively became 
numb. He blocked out the negativity surrounding him, and he credits his academic success to a few key strategies.

\section{Donald's Navigation Strategies}

Donald was determined to be successful and over time, he built some navigation strategies that helped him attain success. Those strategies included (a) developing strong self-agency, (b) learning how to code-switch, (c) knowing which adults to ask for help from, and (d) choosing a high school that he felt was best for him.

\section{Strategy 1: Developing Self-Agency.}

Donald emphasized just how much academic attainment was not respected in his community. He recalled being ridiculed by one of his friend's parents for having a good report card.

[W] show our report cards. I won't mention names but [my friend] shows his report card, he had a 2.0 or something like that. [My other friend] maybe had a 2.5 and I had a 3.9 right? The mother, she looked at his report card and then she looked at the other friend's report card and she was having conversation with it. Then she looked at my report card and shoved it away and pushed me away. There were other people down the street, you would get comments, I'm a kid six seven years old you get, "This is an egghead person, you're one of them brainiacs".

Being smart sometimes made Donald a target. This was a lot for a young boy to process. The message he got was being smart was not okay. However, Donald rejected that notion 
and decided that he enjoyed being the smart kid. He enjoyed being different. He once got kicked out of class for correcting a teacher. Although he got in trouble, the experience was freeing. Donald decided that he was different and that it was okay to be different, and he excelled academically through high school. He did not dumb himself down and actively sought out knowledge as a child.

\section{Strategy 2: Learning how to Code-Switch.}

Growing up in Oakland in the eighties and nineties was tough. As we stated, Donald was a smart guy. However, he learned early on how to maneuver to survive. In school, he learned how to show up. In his neighborhood, learned how to not be a victim. Donald was also an athlete, and he knew that being good at sports also led to him being treated well because being an athlete was highly valued in his community. However, it was not until he got to college that he met a young Black male professor that helped him see code-switching more as a spectrum rather than a denial of part of yourself.

In college, Donald was still had not learned how to deal with emotions. He had always been taught that they were a liability in his youth. In college, Donald had a professor that would challenge him in a new way. The professor was a young Black man more similar to Donald then he was different. He challenged Donald,

But I took [Dr. Cole's] class (no relation) and [he's a] brilliant brother, brilliant, right? What ended up happening is I knew how to navigate the streets. I knew how to navigate social settings, but I was still from East Oakland mentally. Right? He presented this whole other person that I could be. He was calm, he was a 
normal dude, he listened to Snoop, right? I walked into his office one day, and [he was listening to] Gin and Juice. And I was like, "You listen to Snoop?" He's like, "Yeah." And in my mind, I'm thinking like, "You're a normal human."

For Donald, the mere image of his young professor listening to a rapper he too enjoyed opened him up to the possibility of being both a scholar and his authentic self at the same time. Donald never learned how to manage his emotions nor his ability to code switch. He seemed to see it as a switch whereas Dr. Cole exemplified code-switching and authenticity more as a spectrum. Donald continues,

I had all this anger and I was taught to be militant and I was taught to be all these things because that was the way I was taught to get through things. And that's the way I handled things. [Dr. Cole] was introducing a new way to being sort of this professional person that I was becoming and add on the layer of African American and then add on another layer of being a man. I modeled myself after that. My friends saw the difference. I started to change, and I started to adopt ... not mannerisms, but some of the way that he carried himself. I didn't have to be this aggressive person. Again, I was never a street dude, but again there's a certain sort of an edge that you have when you come from communities like I came from. I was able to sort of get through that. I realized that that was a shield or a mask that I was wearing in order to appease and survive in an environment that I was no longer living in. That was no longer my reality. Right? 
Donald, now having a guide, was able to grow his individuality while also coming to grips with the duality of his whole self. This skill allowed him to travel back home as well as teach in Japan. This strategy helped Donald become the academic and community success story he is today.

\section{Strategy 3: Building relationships with adults with academic access.}

Donald learned that there were power dynamics inside his school building where certain adults had the power to help him progress. Donald learned that certain teachers could make life easier at school and offer access to things that every student may not be getting. Donald discussed how he sought out these people,

When I first got in to school, I realized the teachers played a significant role in determining who had access to what. I don't know how I figured that out, maybe it was a conversation that happened, I'm not sure I don't remember that piece. However, I figured it out. When I first got to Emery [high school], I made sure that I identified which teachers play the key roles. When I first got there it was, coach Campbell who was our football coach and our PE coach, and then also to a lesser degree, it was Mr. Burris.

Through their relationships, these adults helped Donald navigate through school and graduate at the top of his class. Through his relationships and his athletic ability, he was recruited by colleges for both football and basketball. He achievedgot great grades. He was able to stay out of trouble. 


\section{Strategy 4: Choosing a high school outside of his neighborhood.}

Donald was strategic in the school that he chose. Donald actively chose not to attend the high school near his home. He felt that he knew too many people there and he would not be able to focus. In addition, his best friend Tracy attended a school on the other side of the city called Emery High which sat on the Emeryville-Oakland border.

It's crazy. So, for me, so I took the bus and [train]. So, I'd leave my house at about 6:15 [in the morning] to get to school at 8:00 or whatever it was, 7:30 or 8:00. Did that back and forth. Had I gone to [my neighborhood school], it's a very good chance I would [have gone down the wrong] path because again, a lot of the people from all the neighborhoods, I'm close with. I went to Brookfield with them. I went to Madison with them and if not, I know their older brothers from my older brother. East Oakland is not that big and everybody kind of knows each other.

Donald's reasoning for traveling nearly two hours away daily is that he felt he would have a better chance of being successful. He worried that he would have fell into the same bad habits that a lot of his neighbors did. Whether that is true or not, the results are the results, Donald became a doctor and one of the only people in his neighborhood to go to college.

\section{Residual Impact}

Donald has become a scholar that has studied internationally and now leads a successful organization. However, there are residual impacts from the early traumas 
Donald faced that he had to deal with. He had to deal with issues of identity, imposter syndrome, his coldness to others, and the massive fears he has of his son wanting to adopt a street life. These are issues that came up often throughout his life that have were not handled in the moment.

Donald struggles with identity issues. As a Black kid growing up in East Oakland around other Black kids, Donald was told he was weird because he enjoyed learning or spoke differently. It is as if others thought Donald felt he was better than them. In order for Donald to function, he had to adopt a mentality that protected him,

For me, I was always a little bit weird but I adopted this attitude, fuck you. Right, if you don't like me, fuck you. Right, I'm a little bit strange, I'm a little bit quirky. Cool, if you like it, cool we can get along. If you don't, that's cool too. If you have a problem with it, what do you want to do about it?

When Donald was in college in Hawaii, he had to come to terms with the impact of his identity issues. During his time in college, he had a young Black professor that helped him confront his identity issues. Donald reacted to things with anger. It helped him get through tough times growing up. It was not until his Black male professor pushed him to think differently that he began to find healthier ways to deal with problems. Here, Donald explains an interaction he had when his professor held him accountable for his poor study habits,

That first semester, he was sort of observing me and I took his class and I remember my first presentation I did in his class, it was supposed to be 15 
minutes, turned out being 50 minutes or something like that. He gave me a C, I was pissed off, I was like, "Fuck nobody likes me." And I'm in that rage moment. The next semester I took his class. Actually, after that situation, he and I had a conversation. He was like, "No, how long is the presentation?" I was like, "It was supposed to be 15 minutes" He was like, "You went 50, how can I give you an A?" And I was like, "Alright." That makes sense, but I'm still mad. But again, I had all this anger and I was taught to be militant and I was taught to be all these things because that was the way I was taught to get through things. And that's the way I handled things.

Donald spent significant time questioning what it meant to be Black and what it meant to be a man. This introspection did not happen before Hawaii, and he realized the anger that he had built up was due to these issues.

\section{"I learned I was 'Inner-City Smart”".}

During his time in Hawaii, he also had anger about being what he called, "innercity smart". Donald explains:

So, I convinced myself that I, although I was doing well at Emery, I was something called inner city smart. I don't know where that came from that's something that I convinced myself existed and that's what I convinced on myself that was. I get to college my first year and instead of diving head first in and saying, okay, well you know what, I'm [going to go] here and really learn how to 
study and do all these things, I disengage. So that way if I fail I can be like, well shit, I didn't try that hard anyway, I gave myself an excuse.

Donald was confused as to how he could get great grades in high school and be at the top of the class and then when he enrolled in college, he realized he was so far behind everyone else academically. This created a complex where he felt imposter syndrome and he admitted that he still struggles with it at times now.

"I am a very cold person".

Donald has residual trauma from being rejected as a child for being different and being abandoned by his father. He says that for him to cope, he had to adopt a cold mentality,

I'm a very cold person. I think part of that had to do with the relationship with my father... What I mean by cold is it takes a lot for me to open up. I don't share a lot about myself. I'd rather have a complete conversation about you before I open up and share anything about myself. Most times when I'm having conversations, people think I'm sharing about me, I'm just asking questions about them. Part of that is because to use a biological analogy, the heart is a very sensitive muscle, it's strong but it's sensitive right? It's protected by the rib cage. The rib cage again is strong but it's prone with nerves and all that stuff, it's sensitive to the elements so then we have skin on top of it right? The same way that heart is protected by all those different layers, I protect myself right? Then depending on who that person is and how much I trust that person, I'll let them in accordingly yeah. I mean I 
think having those experiences, my dad leaving when I was essentially two and not coming back.

In order to survive, he had to deny his feelings and emotions because there was constant reinforcement that Black males were not supposed to feel or be emotionally impacted. Donald admits that he still struggles with this today.

Donald fears rejection from his son. Donald is now a father of two biracial children. He has a son and a daughter. He discussed his fear that sons tend to reject their father. Donald rejected his father figures growing up and worries his son may follow suit. Donald confessed that he worries that his son will learn more about where he grew up and be attracted to the street life. He is happy for his academic success and the life he has created for his son, but it has created real anxiety for him. Donald explains,

[My son's] trouble is going to be very different. He speaks two languages, right, my wife is Japanese. He speaks two languages. He understands both cultures, right. His struggles are going to be different. What I'm fearful of and this is another piece, if the need to validate his Blackness, if he feels the need to validate his Blackness comes through, living some component of the streets, that can suck him in. And that is terrifying as a father.

Donald went on to explain why he feels this way, I have a cousin. His mom does extremely well, she makes right now, probably about $\$ 30,000$ a month. Does really well and has for a long time. He went to [a private school], right. Dropped out and decided he wanted to follow the street life. 
There's no rhyme or reason. There's nothing that a person could do, to have a conversation with. Now he's back on track and now he's getting himself together. But for him, in order for him to reach whatever milestones he wants to reach, he needs, he felt like he needed to go through that other side because it validated him as a Black man.

Donald explains that he fears that his son will have similar identity issues since he is biracial, has traveled across the world, and values education. He fears his son will try to overcompensate to try to fit in.

\section{Key Takeaways from Donald's Story: Good Kid, M.A.A.D. City}

In looking at Donald's story, it is important to understand the complexity created by the environment, the journey of self-identity, and the role [and eventual toll] of codeswitching. Donald was a good kid growing up in a time where street survival was particularly primal for Black people living in poverty. His bright-eyed wonderment and joy of learning was not welcomed and often was rebuffed by both his neighborhood and his own mother.

When his mother prevented him from being in the GATE program, she was not trying to be mean or dismissive, she was being protective of a Black boy that lived in a world where she knew he would become a target. Simply put, Donald's mother was not raising a scholar, she was raising a survivor.

The intuition Donald's mother built in him shown through in his ability to code switch while also building his self-identity which was defiant of the current era and time 
in which he lived, or as Bronfenbrenner calls the chronosystem. Had Donald been 20 years younger where the cultural climate was much different and being smart did not make him as much of a target, his experience may not have been so jarring. What makes Donald special is his ability to form the ability to build enough resilience to walk in multiple identities at once.

The brilliance in what Donald was able to accomplish, along with millions of other little Black boys, was his interpretation of code-switching. Some may think of code-switching as just that, a switch but it is more complicated than that as shown by Donald's story. He figured out that it is more of a spectrum that has to be adjusted where both sides of the identity must constantly be present.

Dr. Cole helped Donald understand the spectrum of code-switching when he presented himself as a professor that still loved hip hop music and being his whole self. The clear presence of representation for Donald helped him understand that the could be multiple things at once. Black boys need examples to show them how to be themselves while also being able to successfully navigate society. As we see with Donald, when that is absent and Black boys are forced to figure it out on their own, they may find success, but it will be a road full of anxiety and emotional suppression. We see this with Donald's fear that his son will reject him and embrace a negative lifestyle because he is biracial. The trauma experienced in Donald's upbringing is haunting him into fatherhood in subtle ways. 
In conclusion, Donald came of age during a time when the crack epidemic had major impacts on both his neighborhood and the people in it. Although he steered clear of drugs and the street life, he still had to gain extra layers of resilience that helped lead him to academic prominence but has also had a lasting impact on him even today. Throughout his education journey, Donald knew that how the adults in the building felt about you mattered and could make life easier or more difficult. The strategies he used to navigate his education are replicable but also came at a price.

\section{Antwan, Richmond}

The path to becoming Dr. Antwan started off rough as the trauma of the crack era had an impact on Antwan's early life. Today, Antwan is a loving father, a husband and a scholar. He works in academia and just published on STEM education. Antwan is a reserved gentleman today, but you can tell, through his mannerisms, that he was much more active in the streets earlier in his life. Throughout our interviews, there were moments when he was discussing a topic and something was happening internally. It was as if there was an internal meter that gauged his control. As he spoke about certain situations, I could tell he was revisiting it emotionally, and he would take time to bring himself back. Antwan's story explores the impact of drugs on the Bay Area, his early traumas, and how he eventually became a scholar.

\section{Antwan's Family Background}

Antwan experienced a lot of trauma early on as a result of the Bay Area climate amid the crack era. Antwan was born in Oakland, CA in 1975 and lived in East Oakland 
for the first four years of his life. He lived throughout the Bay Area including San Francisco and Oakland, but he spent a significant amount of time living in Richmond, California. Antwan grew up in Richmond during the eighties and saw the streets drug of choice graduate from heroine to crack-cocaine.

As a result of the influx of drugs, there too was an influx of violence in the community. In 1991, there were 62 homicides in Richmond with a population of roughly 98,000 . This figure was seven times higher than the national average. The portion of this violence that was drug- or gang-related increased dramatically from just five percent to $55 \%$ between 1989 and 1991 . During this same time period, the amount of gunshots fired in the city of Richmond also grew $51 \%$ (Office of Juvenile Justice and Delinquency Prevention, 2018). Antwan came of age amid this violence and explains his experience, So, so, so yeah, so along with the crack epidemic, right? There was this kinda warranted violence, right? it was like the old west of something in some respects. So, I was really desensitized in gun violence, right? I had seen people shot already at that time. I had guns drawn on me, cuz I was robbed at gunpoint. I remember one time we were at a park. We were at a park in Fairfield and this is when we had an influx of Southeast Asian folks right? This is when the Hmong, Laotian and Cambodian folks first started to pop up on the scene. Now, this is my first recollection, but they were still a fixture in Richmond around that time. And so there were gangs, we had Latino gangs, we had sons of death, which was Southeast Asian gangs. And I remember a guy came to the park and he had his 
gun out and he was scared, [and he said], "Hey you guys seen... something, something, something? and I'm like, "Nah man." But, nobody moved! Cuz he wasn't trying to shoot us, nobody moved.

Antwan shows the level at which he and his peers were desensitized to the violence happening. In Antwan's summation, gang members with guns were only trying to shoot their target. This shows a difference in the social norms of Richmond at the time versus the suburbs where the mere sight of a gang member with a gun elicited fear, not the indifference displayed by Antwan and his peers. When discussing why he was so desensitized, Antwan simply stated, "Cuz we were hearing about drive-bys all the time." During the apex of the crack era, especially for children that were coming of age during this time such as Antwan, the heighted amount of violence in the community was simply the new normal.

Antwan also notes that Richmond has oil refineries and they would catch fire and pollute the community. A large number of people who grew up in Richmond during the same time ended up with asthma and other respiratory issues. The problem was so bad for poor Black people in Richmond that many of them would get settlement where the city government had to pay Richmond families. Antwan got asthma, and his mother used their settlement money to send him to private school.

Antwan and his mother have always been close, and she always had his back even as they struggled socially and financially. Antwan's mother had him when she was 23 years old and his father was 40 . His mother was always very religious. For instance, she 
would pull him out of school for Halloween because she did not want her son partaking in those festivities. Antwan consistently had behavioral issues in school, but his mother always showed up supportive of her son. It was important to her that he knew she would always be there for him. An example of this is one time when Antwan got in trouble and the school called his mother. Antwan remembers,

[The teacher told my mother], "Well, your son seems to have no regard for personal safety, and I wanted to know if he's on drugs." And my mom looked at her and said, "Why you want some?" and the lady just stormed out at that point. But that's exactly how my mom was, she always advocated for me! Whether I was right or wrong. Like I got in trouble with her but you would not know that. You know how some parents will be like, "Boy you better...you know what I mean? that's not how my mom got down, you know what I'm saying? She said, "I got my son's back I'll deal with him when I get home, but you're not going to going to sit here and, you know, disregard or disrespect or castigate my son in front of me.

Antwan's mother was away from home a lot due to work, so he had to fend for himself but he has always seen himself as a protector of his mother. He constantly reflected that his mother sacrificed and did the absolute best job she could do for him.

Although Antwan's birth father was not as present, he was a major source of early childhood traumas and shaped the concept of manhood for Antwan. As stated earlier, Antwan's father was nearly twenty years older than his mother. Antwan describes his 
father as a guy who ran the streets. His nickname in the streets was Fast Eddie. He was from East Oakland and sold drugs and robbed banks. Prior to meeting Antwan's mother, Fast Eddie spent time in prison for killing someone with a hammer. He was arrested again for robbing banks when Antwan was very young, and Antwan was informed that his father had died. It was not until his early twenties when Antwan received a letter from his father that Antwan learned his father was in fact, not deceased why he went to prison. Antwan's father struggled with heroine. Antwan and his father reconciled for a brief period. He contracted AIDS from intravenous needle use. Tragically, Antwan's father contracted AIDS from intravenous needle use and later died from complications from AIDS when Antwan was 23 years old. Antwan had rediscovered his father just to lose him again,

I wish I hadda had an opportunity to spend more time with him. Uh, but when he came around when I was 23 , you know I was in the midst of some real years of self-centeredness, and I wasn't, I wasn't worried about what anybody else was doing. I was worried about what I was doing at the time. One of the regrets I have is that I didn't reach out more and try to uh... You know I think about it though sometimes. Cause I got these four boys, man. My father won't know them. So I just imagine sometimes, uh what, how much my dad would have if he got to meet my boys. I got four boys, man. My boys are amazing ...And he would have you know here from my wife's parents, who are phenomenal parents who've been married forty plus years. And uh, uh being a grandparent is like the best thing in 
the world. It's like starting over. You know, all the mistakes that you made as a parent, uh you know you don't have to hold to that anymore because you have these new lives that you can participate in shaping and nurturing.

Antwan feels that his father could have had a new shot at life and to make up for the early mistakes he had. The regret Antwan feels for not trying harder to connect with his father is palpable.

\section{Antwan's Early Traumas}

Antwan dealt with a multitude of trauma in his life that including violence, loss, and setbacks. This section discussed some of the biggest challenges he has had to face on his road to becoming a scholar, a husband, and a father. There were too many stories to choose from however, Antwan wanted to highlight the ones that had some of the most lasting effects while also helping to describe what the Bay Area looked like for him in his youth.

There was a year in which Antwan's mother was in an abusive relationship. The stepfather came around when Antwan was about four or five years old. He was a Vietnam veteran, and the war had a lasting negative impact on him. He was an imposing figure and a raging alcoholic. He was 6’2,230 pounds of muscle. The relationship him and Antwan's mother produced a child and an excessive amount of physical abuse. The worst instance was one time when Antwan's stepfather beat his mother so severely that the image of her suffering is permanently burned into Antwan's memory. He recalls, 
He beat my mom. I remember one time, you know I have a book. I wrote about this in the book like, kicked a hole in her throat. You know back then everybody used to wear pointy toed shoes man and it's just like tissue was coming out. Like I'm a kid and I'm seeing this stuff man.

This memory has played a role into his desensitization to violence.

Antwan hated his stepfather. He used to pee the bed as a kid and his stepfather threatened to send him to school soaked in urine if he had another accident. A young Antwan tried to avoid having another accident but was unsuccessful and eventually urinated on himself in his sleep. His stepfather, true to his word, sent Antwan to school soaked in urine. Antwan left the house like he was going to school but he just hid out until his mother came home from work. Antwan's mother finally escaped the relationship which led to them and Antwan's new little brother to a battered women's shelter that continued to make an imprint on Antwan's psyche.

The battered women's shelter was designed to be safe and help women get their lives back on track. There were strict rules so the abusive men could not find the shelter. The rules of the shelter included curfews and not disclosing the location to outside people. However, Antwan was also told repeatedly not to eat sugar before going to bed. Antwan thought this particular rule was peculiar, but he soon learned why the rule existed,

And uh, and then one night we woke up and it was like this blood curdling scream man, and everybody ran to their room, cause you don't know, cause you weren't 
supposed to tell, they weren't supposed to tell the men in their lives where they were cause these were violent men they would come back and they would come back there would be problems right? And so we don't know. So all the women are banded together, you know, so it was like so we would go figure out what was going on. And uh, we ran to their room and there was a little girl whose lip was bleeding, because one of those giant San Francisco rats was chewing the sugar off her lip! That's why you couldn't eat candy before you went to sleep. And so, uh, so that place was crazy man it was like a nightmare.

Antwan was visibly shaken as he told this story. His voice cracked, and there is a mix of sadness that is overpowered by rage. This event signified two things for Antwan. First, he developed deep guilt for feeling like he could not protect his mother when they were in the shelter. It is common for adults, who experience childhood trauma, to have lingering memories that shape their adult relationships. Second, this event left an imprint on Antwan and caused him to take extra care to protect the people he loves. Protection became a priority for Antwan and that played out as Antwan got older. His temper grew shorter as he entered his teen years and the violence around him became more normalized.

As Antwan came of age living in Richmond, he soon became desensitized to the gun violence going on around him and to him. Antwan heard about so many people being shot that it started to have no impact on him. He reflected on the times in which he realized just how desensitized he and his friends were to violence, 
Cuz we were hearing about drive-bys all the time. I remember at one point in Richmond, this was late 80s, maybe even 1990 that 25 people got shot in one week. They didn't all die but 25 people got shot in one week cause it was Indian Summer it used to get hot, cats start wildin', you know what I mean? It was the craziest thing. Like nobody would run and we would see people with guns. I used to carry a big gun. Around that time, I was looking in my backpack for a pencil and I had a pencil. My backpack was entirely empty except for two items, I had a Glock and I had a pencil.

It was nothing new for Antwan to carry guns or get into fights. As a child, Antwan was into boxing and martial arts, so fighting did not bother him. He had a lot of anger built up and he needed an outlet for it. Antwan and his friends were not intimidated by guns or violence as it was just a part of life and they had no trouble partaking if the situation called for it. Antwan credits the anger he and his friends had to the poverty and hopelessness of the community, the drug infestation, and the sense of survival most people in the community had. Antwan's experience in school helped him get to this disposition.

\section{Antwan's Educational Experiences}

Antwan was not very successful in grade school. His academic success came later in life. This section will discuss his experience in grade school and then explore the navigation strategies he utilized to get back on track academically to eventually earn his 
Ph.D. By looking at his journey through K-12 education to his transformation in junior college, this section gives a closer view at how perseverance is not always a straight line.

As a young student, Antwan moved a lot. He was always recognized as being a smart child, but he just did not apply himself. Early on, Antwan was chosen to be part of the Gifted and Talented Program. He felt school was a reprieve from things going on at home. Antwan admits that although he was not a fan of class, he loved going to school. He enjoyed the social aspects of it. Elementary school came easy for him. It was when he progressed to junior high school where things began to take a bad turn.

Antwan remembers hearing an adult say grades in junior high did not matter. As a result, Antwan did not really apply himself. At this time, Antwan's mom was single and worked a lot to support their family so she could not be as vigilant. She had to trust Antwan to do what was required. What she did contribute was she always exercised her ability to get him into the best school possible rather than the closest school. This usually meant that Antwan often went to different schools than his peers. It did not take long before Antwan started cutting most of his junior high classes. He would continue this practice into his high school years as well.

In high school, Antwan's mom got settlement money from the Chevron lawsuit and was able to send Antwan to a small private school. It did not last very long as Antwan continued his rebellious streak. He cut often and was eventually kicked out of school. Antwan ultimately attended three high schools and was kicked out of two of 
them. He got arrested multiple times, once for stealing from Nordstroms. When he graduated high school, he stepped away from school for a few years.

Antwan was a late bloomer academically and did not take advantage of his time in K-12. However, he refocused in community college and utilized the following strategies that would lead him to the academic success he now enjoys.

\section{Strategy 1: Never too late to do the right thing.}

As stated earlier, Antwan was a late bloomer and matured later in life. He was apathetic in high school because he knew community colleges basically accepted everyone,

There were certain things that I would pick up on, right? Like if you were gonna go to community college anyway, it didn't matter what you did in high school, because you start over, and they look at your community college. I didn't care about school, and I literally went to school from 10 to 12 my senior year, because I was finished with everything else. Well, I'll just go to community college and figure it out from there."

Community college offered Antwan the opportunity to get back on track educationally. In fact, he tried a few times and every time he failed.

I started at Contra Costa College, and I was in these remedial classes. I never took the assessment test. I left. I didn't leave willfully. I got dismissed from Contra Costa College because I had a 1.1 GPA for too long. That's not easy to do, and what stopped me from having under a $1.1 \mathrm{GPA}$ is that I had passed a badminton 
class and a weightlifting class, and so a solid 1.1. I think it was this. My first couple of years at community college were tumultuous. I didn't have any study skills because earlier on, in elementary school, to a lesser degree in middle school, but then to a greater degree in high school, right. Middle school is really hard academically. I could just get by because I was kind of smart, or at least that's what I was told, but then in community college, it was different. You actually had to study. I had never developed any study skills, and so I struggled. I would go to get help, and the help that I received was never particularly helpful. [So] I left. Antwan would go on to fail out of community college a few more times, but when he matured enough and decided that he actually wanted to finish, the community college system was there for him. He focused, got his grades up and then prepared to transfer, I applied to San Francisco City College, that's not true. I applied to San Francisco State and I applied to UC Berkeley. I got into both. I was determined to go to San Francisco State, because I had talked to so many transfer counselors, and they dissuaded me from going to Berkeley. He wouldn't have even asked me, he was like, "Are you sure?" Something along the lines of, "Are you sure you want to go to Berkeley and compete with some of the brightest minds in the nation? You have to find a school that's right for you."

Even after getting accepted to UC Berkeley, he was actively dissuaded from attending the prestigious university, 
All the way up until that time, I had been talking to counselors about transferring to Berkeley. They were like, "Have you thought about Hayward," it was still Hayward at that time, "Have you thought about San Francisco State? Sonoma State has this program." I'm like, "Yeah, I want to apply to all those places too, but what do I need to do to go to Berkeley?" I talked to like 10 counselors before anybody would even humor me. I was 30 at the time.

Despite the naysayers, Antwan chose Berkeley. This process actively started his journey to his Ph.D.

\section{Strategy 2: The support of a loving spouse.}

Antwan's wife makes him feel like a superhero. She constantly encourages him and pushes him towards his goals. It is his wife who has been next to him the entirety of all his academic success. She is also a graduate of UC Berkeley and she was there to actively support him throughout his journey. When Antwan started at UC Berkeley, things started off rocky,

What happened was, I called my wife crying. I'm not ashamed to admit it. That class was so hard. At community college, in order to get into Berkeley, you've got to be killing it at community college. I got my first two midterms back, I got D's on both. I'm like, "Man, what am I doing here? I should have went to San Francisco State." I had internalized that. I was like, "I should have went to San Francisco State." I'm not denigrating anywhere, but that's just the other place I got 
into. I was like, "Man, I should have went to San Francisco State. I could just get through this.

But she just encouraged him over and over. She was his rock. She was also the main person supporting him when he started thinking about the Ph.D., I finally told her [I was thinking about the Ph.D.]. I was hoping she was going to scoff at it with me [but she did not]. And this indisputable, she is, her presence in my life is a constant reminder of God's love for me. I just can't say enough about how amazing she is. She really helped me through the situation as you know I love her with my entire heart.

This passage highlights how much confidence his wife gives him to do things he is uneasy about. Throughout our interviews, Antwan constantly referred to his wife as a source of strength.

\section{Strategy 3: Being held to a higher standard.}

Antwan talks about the love for God and his wife fiercely. He feels that she saved his life. But in order for him to be allowed to marry her, his now father-in-law required him to graduate from UC Berkeley.

Our relationship started when I was 23 , and there was nothing going on then. Rachel's four years younger, she was 19 , she was at $\mathrm{Cal}$ at that time. She's the apple of her father's eye. He just wasn't for it. He was like, "No matter what Antwan does in life, if you want to marry him, you'll never have my blessing." It came out then that we had some interest in each other. We went to the same 
church. You can get married, but everybody has to be onboard, her parents, the church community, it was that type of thing.

It was this social pressure and expectation put on him by his now father-in-law and his church community that pushed him to achieve what he thought to be impossible.

\section{Strategy 4: Wanting to set an example for those you love.}

As Antwan listed the impact both his wife and her father has had on his academic success, what pushed him over the top was his love for his children and wanting to offer them a model of success. So, Antwan did not stop after community college or his undergraduate degree from UC Berkeley; he kept going. The love he has for his sons made him more focused and disciplined. Antwan transformed from a nonstarter in high school and community college to a scholar largely off the desire to achieve in front of his family.

At this point, I've got responsibilities, so I was serious about school. What happened was I just really knew that I needed more for my experience here, because those two years weren't enough. I had been building towards that for so long, I was like, "Man, I'm not ready to be done with this yet." I wasn't afraid to go get a job or any of those other things. I was just like, "I need to be at Berkeley a little bit longer."

These strategies are more cerebral and spiritual, which makes sense for Antwan. He is very religious and credits all his success to God's grace and mercy. Antwan has worked hard to atone for certain things and the early traumas still weigh heavy on his heart. In the 
next section we will explore the residual impacts from the traumas in life and how they still show up today is explored.

\section{Residual Impact}

As we have discussed, Antwan's life was filled with extreme levels of trauma. As he grew and matured, he used his experiences to help others, yet there are still many lingering effects from the trauma. This section explores those residual impacts and names how they show up in his life today.

Antwan has strong fears around fatherhood. Antwan has a lot of residual issues from the encounters with both his father and stepfather. He constantly worries if he is doing a good job being a father since he did not grow up with the traditional nuclear family model. To combat his insecurity around being a good father, he tries to lean on his religious teachings to guide him as much as possible,

That's what I've become [clearer] about spiritually. The man of the house doesn't necessarily, even in this Christian home, doesn't necessarily mean that I'm right when situations arise. It means that I need to be the first one to submit to the Father's will, to seek through prayer and submit to the Father's will. For me, I hope that my sons are able to see that.

Antwan still feels that he often fails in this area, and this takes a toll on him because he is aware of just how impactful trauma can be during the developmental years for his sons. 
Antwan still struggles with deep anger issues. Antwan has experienced amazing growth in controlling his temper and reactions to things. However, he offers a sober reality to the way he views the world after growing up around the normalcy of violence in which he did,

For me, some of the residual effects of growing up in an environment that was, there was a lot of love there, but I don't want to romanticize it either, there were a lot of components of it that were detrimental as well. I grew up around a lot of violence and sometimes I don't respond to things ... Let me say, because of the work that I do and some of the kind of accomplishments, educational accomplishments I have, people expect a certain amount of enlightenment from me. I hope that I'm able to exhibit that.

There was a time recently when Antwan's temper was tested. There was a situation involving one of his sons and Antwan almost had a relapse to his early twenties. There was a grown male family member that reprimanded his son, and Antwan was ready to put hands on this adult. His wife had to physically get in between the men. Antwan acknowledges that he must handle situations better as his son witnessed the exchange.

\section{Key Takeaways from Antwan's Story: Late Registration}

Antwan is battle tested. He was built to be a protector and often feels responsible for those around him. Antwan differs from our other two cases as he is the only one that took the community college route. He was also the most active in street life. Antwan's pains and experiences with violence are deep and lasting. Very rarely does one forget 
watching his mother bleeding out from the neck after she is beaten. A child also never forgets living in a shelter and witnessing a rat chewing on a little girl. Antwan internalized all of this and somehow blamed himself although he was utterly powerless in both moments. Should it come as a surprise that he showed bits of rage in school?

Antwan represents the student with the pent-up rage. Brilliance lives under that rage, but it resided deep below and was not able to fully shine without Antwan's unwavering faith in God and the love of his wife. For kids like Antwan, it is no wonder they want to control as much of the environment as possible. That may manifest itself through fights, being disruptive in class, or cutting class all the time. Antwan spoke of this need to control when describing his love for his sons. He wants to hold them as close as possible. If anyone says anything to them, the mild-mannered scholar is liable to revert back to the angsty Richmond kid ready to tear someone's head off.

Antwan is a brilliant, God-fearing man, devoted husband, and father. He was visibly emotional anytime he spoke about his family. He loves hard, but he almost slipped through the cracks. The key takeaway from this story is to use Antwan's oral history to picture the many misunderstood boys under similar duress as a young Antwan.

\section{Summary}

This chapter addresses the first research question, regarding the navigation strategies of our subjects by presenting their narratives of success. These narratives of Black men represent their unique stories that are not steeped in negativity. The stories are 
stories of success and triumph for these three men who represent the top one percent of academic achievement in the world.

There are five takeaways across the various case studies regarding the men's strategies for academic success including (a) strong mothers, (b) a strong sense of identity, (c) strong adult allies, (d) exercised school choice to achieve better education, and (e) the ability to intrinsically value education themselves.

\section{Strong mother figures.}

Having a strong mother was significant in each case study although it manifested itself differently amongst our subjects. In all three cases, the mother figure was a beacon of strength to the young men. In all the cases, even though each mother experienced tremendous hardship, none of them fully succumbed to crack addiction. Antwan and Demarcus both discussed the bonds that they shared with their mothers early in life. Antwan recalled how his mother always had his back. In many cases, she was the source of his early confidence. Demarcus discussed how his mother held their immigrant values while constantly exposing him to all the arts New York had to offer.

Donald's relationship with his mother seems a tad more complicated but just as relevant to the strong mother motif. Donald's mother made him tough. She was a representation of what was required to survive in the context in which they lived, and every decision she made was through that lens. Donald's mom kept him out of the GATE program not because she hated education, but because she knew it would make him a target in their circumstance. The toughness Donald's mother instilled in him was key in 
helping Donald establish his strong sense of self that aided him in earning his doctoral status.

\section{Strong sense of self.}

All three subjects showed strong signs of self-identity. Demarcus accepted early on that he loved the arts and his Bajan roots. The confidence he gained in himself is what led him to stand his ground against Mayor Giuliani even though he had to withstand the negative backlash that came from it. He was able to still graduate and go on to finish law school. However, it was that same strength that led him to leave behind a lucrative career to build the type of organization that best represented him.

Donald showed his strong sense of self by not dumbing himself down even though he was ridiculed by his community and at times, his family for being smart and academically successful. Donald went on to learn who he was in the context of home environment and academic environment. It was through his strong sense of self that he knew his uniqueness belonged in both.

Antwan may be the best case for the importance of self-identity as he was the late bloomer academically. It was when he came to terms with his role as protector and wanted to really walk in that calling that he was able to complete his college comeback and eventually become a Ph.D.

\section{Strong adult allies.}

In each case study, there were adults within the subject's academic world that offered a sense of possibility, moral support, a pathway to follow, and their navigational 
capital to aide our featured Black men. In Demarcus's case, there were many examples of strong adult allies which included his teachers and his neighbor. Antwan's strong adult allies came in the form of the woman that would become his wife and in her father. They helped him see what was possible and offered a potential path towards his goals. Donald also had these same types of allies, whether it was his music teacher in high school or Professor Cole in graduate school.

\section{Exercised school choice to achieve quality education.}

In all three cases, the subject or their parents rejected their local neighborhood school in search for a more quality education. In the cases of Demarcus and Antwan, this was done on their behalf by their mothers, while Donald made the decision himself. After Demarcus's mother saw that there were better school options for her son, she learned how to seek them out. She chose what she felt was best as evidenced by Demarcus and his sister attending different schools at times even though they were only a year apart. Antwan's mother was similar. After winning a lawsuit, she took money from the settlement to place Antwan in a private school. Donald went about school choice differently. He lobbied his mother to attend school across town to be with his friend Tracy, and to experience life outside of just the neighborhood he grew up in.

In each of these cases, exercising school choice helped cement what may be the most important factor that made a difference for each of these Black men; it helped them to intrinsically value education on their own. From the data collected, it is important to note that whether the school performed better was not as big of a factor as the gesture of 
explicitly prioritizing the value of education. Each case study remembered these moments as key, which leads into what may be the biggest takeaway.

\section{Intrinsically valuing education on their own.}

Each subject came to value education on their own. All the factors listed are important but what seemed to be most important was that the individual personally saw the value in education. For Demarcus, his mother and neighbor helped connect the idea of education to being successful. The value of education was clearly articulated in Demarcus's life. Donald also decided early on that education was worth the ridicule. However, Antwan best exemplifies this takeaway. He was the late bloomer. He had the love of his mother, access to better education, and positive adults cheering him on, but it was not until he personally embraced what education could manifest for him that he completed community college and went on to earn his Ph.D. Without this intrinsic knowledge, it is likely that Antwan, nor the other two subjects would have completed his doctoral degree.

In the next chapter, the synthesis of these experiences helps address the second research question, was grit enough? In the next chapter, the case studies will take a deeper look into the role grit played not only with academic success, but beyond as these scholars became husbands and fathers. The case studies provide enough data to draw conclusions about the long-term impacts, both positive and negative, of having to be as resilient and gritty as these men. 


\section{Chapter 5: Findings}

In this chapter, the purpose of this study is restated and the findings from the oral histories that were conducted are summarized. After detailing the findings from the study, there is a discussion on how those findings coupled with literature can be applied in the service of other Black boys today. The various ways educators, parents, and other caretakers can apply the findings in practical ways are explored. Finally, the chapter closes with ways this study leads to future research.

\section{Restating the Purpose of the Study}

The purpose of this study was threefold: (1) to examine the strategies and navigation skills of three Black males, who against all odds, successfully navigated public education to attain a doctoral degree; (2) to identify and understand the socialemotional residual impacts that can come from such navigation; and (3) to affirm and illuminate the lives of Black males that have succeeded academically. This led to our two research questions:

RQ1: What strategies enabled Black men impacted by the crack epidemic to survive public education and achieve doctorates?

RQ2: What are the unanticipated social-emotional residual effects as a result of rigid academic achievement for Black boys?

Summary of Findings

\section{Addressing RQ1.}


Chapter 4 addresses the first research question and details the navigational strategies from each case on an individual basis. This chapter offers significant implications for RQ1 across the three case studies in a manner that addresses potential navigation strategies that may be utilized for trauma exposed Black males. In totality, each subject came to intrinsically value education which led to a level of academic agency, the capacity of students to exercise choices over their academic experiences (Berridge, 2017), that guided each subject to the highest rung of academic achievement. In building that level of academic agency, the following navigational strategies were present across all the case studies:

(1) Sought out Quality Education

(2) Strong Self-Identity

(3) Proximity to success

\section{Sought out quality education.}

Each case study illustrates that the fight for access to quality education was a significant factor in each of these men's academic journey. In each case study, the subject had a moment when the parent or the student exercised school choice. In doing so, a strong statement was made regarding just how important quality education was. This study did not look at the effectiveness in the moment of the school as it was almost inconsequential to the student. What is of note is how actively seeking out quality education ultimately led to higher academic agency. For example, Antwan got kicked out of one of his schools for cutting, Demarcus asked to leave his new school because he 
missed his friends, and Donald's new school was not necessarily better than the one in his neighborhood. In each case study, however, each subject reflected on how the change helped crystalize just how important seeking out a quality education was for their success. For Demarcus, it was a reflection on how a professional in his elementary school put her career on the line to help him to attend a better school. For Donald, it was a reflection on how important it was for him to travel across the city every day to have a better chance at learning. While for Antwan, it reflected the fact that his father-in-law would not allow him to marry his now wife. All these reflections led each of the subjects to determine that they had to hold a high standard for the best education, which for Black men of their profile, often meant actively seeking it out.

The extraction of this point to the larger community of Black students growing up in similar settings suggests that the practice of seeking out quality education leads to a stronger sense of academic agency. Even in a failing system, it is important for Black students and families to feel as if they have some type of agency over themselves and are not merely at the mercy of the neighborhood school.

\section{Strong Self-Identity.}

During the interviews, it was clear that each subject gained a strong sense of self throughout his academic journeys. All subjects struggled to define themselves as independent of the external factors that were happening around them. In many cases, students can succumb to the desire of being accepted by their peers which may also be highly influenced by the external factors impacting them all. However, this research's 
case study participants were able to be their full selves despite the threat of what may happen to them if they were incongruent with the nature of the environment. For example, Demarcus never had to hide his love of the arts and dance. He was able to use the arts as an outlet throughout his journey and still does today. The same can be said for Donald. Donald was an amazing athlete and was not afraid to fight. As a result, he was left alone to be able to be his full self when it came to academics. He had enough street credit that he was never severely chastised for always wanting to learn more, and when he was, Donald had the ability to shut others out to protect himself and stay on his path. Antwan presented the best because his case study illustrated what can happen when one lacks self-identity. Early on, Antwan was trying to find out who he was. He was aimless and reckless. However, later in life, when he developed a better sense of self, he was not as easily swayed off his path. At times, he did not know who he was, and he was easily pulled into negative things such as cutting school, fighting, and occasionally getting arrested. It was not until he matured and gained more self-confidence and direction in community college that he displayed the habits of a person with a strong sense of self, and once he did, he ended up pursuing a Ph.D.

\section{Proximity to success.}

By having access to other living, culturally similar figures of success, each subject benefited positively toward academic achievement and longevity. The findings of this study suggest having close proximity to academically successful people is essential to high academic achievement of Black males exposed to extreme trauma early on. This 
finding leads to the assumption that the proximity to Black success helps demystify the process of academic achievement if a student attends poor schools with consistently poor outcomes for Black students. In summation to this point, if the goal is for Black boys to succeed academically, then these boys should be surrounded by Black people that have succeeded academically.

In attempting to answer RQ1, the implications focused more at the individual and family realm of power and agency. The education system still contributes to building broken Black boys that become broken Black men. In addressing RQ2, the focus is concentrated on the residual impacts on these Black men in their pursuit for academic success.

Despite their success, each case study demonstrated residual impact from exposure to traumatic experiences as children. Therefore, Black boys require more than merely academic success strategies, but schools, parents, and organizations must support Black young men with their social-emotional healing from trauma.

In the powerful case studies, we learned of these magnificent Black men and their stories of perseverance, navigation, and hope on their pursuit to the highest of academic accolades. However, academic success comes at a cost for people that have been as highly impacted by trauma as the subjects of this study. These lessons are as important to note as the navigation strategies because the fight for a happy and healthy life does not end at graduation, it only begins a new chapter with new struggles. 
In the powerful case studies, we learned of these magnificent Black men and their stories of perseverance, navigation, and hope on their pursuit to the highest of academic accolades. However, academic success comes at a cost for people that have been as highly impacted by trauma as the subjects of this study. These lessons are as important to note as the navigation strategies because the fight for a happy and healthy life does not end at graduation, it only begins a new chapter with new struggles.

While Chapter 4 focused on the individual impacts, this chapter addresses the second research question by detailing the social-emotional residual impacts of Black men that earned doctoral degrees after growing up experiencing extreme trauma. Each subject in the study suffers from deep emotional scars as a result of both the trauma they have experienced and the discipline and rigor it takes to succeed academically at this level. The deep emotional scars for Black men fitting the profile of this study include:

1. Latent emotional insecurity and heightened anxiety

2. Difficulty in building deep and meaningful relationships

3. Deep insecurity with whether their talent would transfer to academic achievement in white spaces

\section{Latent emotional insecurity and heightened anxiety.}

Each subject highlighted a high level of deep emotional insecurity that, at times, impacted and continues to impact their ability to function and continuously led to debilitating anxiety. For people that fit the profile detailed in this study, this emotional insecurity played out in the following ways. They had difficulty making decisions and at 
times, even now, their decisions continue to be led by fear and insecurity. Their emotional self-regulation at times continues to be off and ill-regulated at the most inopportune time akin to Demarcus when he constantly missed the subtle signs his wife gave him about feeling neglected and being close to leaving. Demarcus was largely led by his fear of ending up like his father and thus overcompensating to be the opposite while, in actuality, he was also neglecting his family, just in a different way.

This latent emotional insecurity leads to heightened anxiety and the consequences that come with it. The heightened anxiety exists as Black males struggle with the newfound duality of their "success" and his former self. Since this success is now the ongoing reality and not a phenomenon or singular moment, the anxiety does not attack as much as it settles into daily life thus constantly attacking the point where the subject may not know he is under attack. In this constant state of anxiety, it is possible for the subject to feel insecure about whether they still fit or belong in their former life, or if they really earned their new spot on the other side of "success". As a Black male who experienced early trauma feeds into the mindset of this false duality, he may find himself trying too hard to fit in with both groups, pushing everyone away, or becoming even more depressed as he no longer fits into any group moving forward. Whether it is referred to as survivor's guilt (Austin, Clark, Ross, \& Taylor, 2019; Covarrubias \& Fryberg, 2015), imposter syndrome (Austin, Clark, Ross, \& Taylor, 2019; Ewing, Richardson, JamesMyers, \& Russell, 1996), or a nuanced version of double consciousness (Gilroy, 1993), it 
is ultimately unhealthy and can be the subject's undoing if it is not recognized and treated with the level of severity it deserves.

\section{Difficulty in building deep and meaningful relationships.}

Individuals that fit the profile of this study struggle to build and maintain meaningful relationships. As detailed in Chapter 4, each subject displayed the lack of the ability to trust others or relinquish control which are both required in order to build deep and meaningful relationships. As men that had to overcome barrier after barrier and often feeling as if they had to do it alone, it is quite difficult to change course into adulthood and operate in a way that forces one to build meaningful relationships.

The subjects of this comparative case study showed signs of being standoffish and have a high desire to be in control. Due to the level of self-agency they needed to get to this point professionally, it is naturally counter-intuitive to them to relinquish any control. Each case study highlighted how difficult it was for these men to lower their guards.

Looking at it from the perception of the study's subjects, it is easier to reject the world before the world rejects you.

\section{Deep insecurity with academic achievements in white spaces.}

In Chapter 4, Donald discussed the idea of being "inner-city smart", which means amongst their peer group in high school, they performed extremely well, however, when they got to college with a diverse group, they struggled to catch up and maintain. Extrapolating this to Black scholars that grew up with a similar profile to the case study subjects, many others feel the same way. Bridge scholars often feel as if they must to 
prove they belong academically, which means not just catching up but outdoing white people. This does not necessarily mean it is something to prove to whiteness and white people, but to themselves.

This may lead to a need to signal success or outperform the crowd. Often for this profile, average is not good enough, and they put pressure on themselves to sit among the elite and eventually, outperform them as well. The early trauma experienced by this profile type has taught them the lesson of competition in the most primal of ways. This profile grew up in neighborhoods where the weak suffered and died. They are familiar with an unkind world that does care about intent but results. This profile is often highly ambitious and aggressive in their pursuit to a happy life and they are willing to enact a degree of aggression and discipline most are not. In all these residual impacts, awareness is important so that which is a source of power does not become their undoing.

For research question 2, there were two implications regarding the socialemotional consequences for these Black men that grew up deeply impacted by the crack epidemic. The three subjects were not personally connected to each other, and they all grew up in different neighborhoods with different family structures. They each had unique paths to educational success; however, each subject experienced residual impacts from childhood trauma.

The findings clearly show is that dormant anger from childhood traumas does not fully subside in adulthood. In each case, this untreated trauma still poses a threat to each man long after they reached the highest of academic achievements, which in this case are 
doctoral level degrees. The three subjects all showed signs that their childhood trauma played a major role in how they developed a pattern of dealing with his anger poorly. Each subject used his anger as fuel to attain their academic goals. However, when the anger was present, the subjects found healthy strategies to help them accomplish their goals rather than righteous anger that can become toxic in their lives when it goes unchecked. The toxic anger played out for our subjects in various ways as detailed in chapter four. For Antwan, he almost beat up a man for commenting on his child's behavior. For Demarcus, he almost lost his wife from overworking at his law firm -which was in part fueled by how his father was not able to provide for his family. Finally, Donald's self-reported that he turned cold and felt that everyone was against him, even people that were trying to help.

\section{The Black Achievement Trauma Tax Phenomenon}

The data provided throughout this dissertation upends a major belief often held by Black families. The upended belief is for Black males growing up impacted by poverty, academic attainment will improve most aspects of their lives, including issues caused by trauma. This study found that to be partly false. While the study did highlight the importance of academic achievement, it also found that dormant trauma does not solve itself or go away once the subject fulfills high achievement, instead, it reappears and poses serious threats in various forms which will be known as the Black Achievement Trauma Tax Phenomenon. The Black Achievement Trauma Tax Phenomenon, or BATT, is the phenomenon wherein people grew up in poverty and experienced high volumes of 
trauma but nonetheless successfully navigated education without actively addressing their traumas pay a great social-emotional price.

The BATT Phenomenon-has three main principles. The characteristics of the BATT phenomenon that were revealed in this study are that for Black males who grow up with extreme levels of trauma (a) the effects of trauma are real and limit one's capacities to perform academically and socially, (b) when left untreated, trauma lingers and can be extremely later in life, and (c) there must be an intentional balance of rigorous academic achievement coupled with healing. Vulnerable populations living in poverty have less access to quality therapy and counseling options compared to populations with means. It can be difficult to get psycho-social supports to deal with the everyday trauma many of the students fitting the profile of the study's subject experience. However, because many of those same children are extremely resilient, the trauma often acts an agent that can be utilized to will the student to success. The student may endure more, to reach their goals. However, as the academic success comes, the trauma does not go away. Instead the trauma goes dormant. The students' academic success is mistakenly taken by others as a sign of excellent mental health. As a result, the student may begin to over-rely on the resilience coupled with skills they have developed as part of surviving their trauma. This strategy may very well work for a while and help the subject grow into an adult with academic and/or professional success. However, eventually the weight of their dormant trauma reappears, and they have a panic attack, nervous breakdown, mistreat their spouse, or some other form of self-sabotage. 
Table 3.3 The Black Academic Trauma Tax Phenomenon
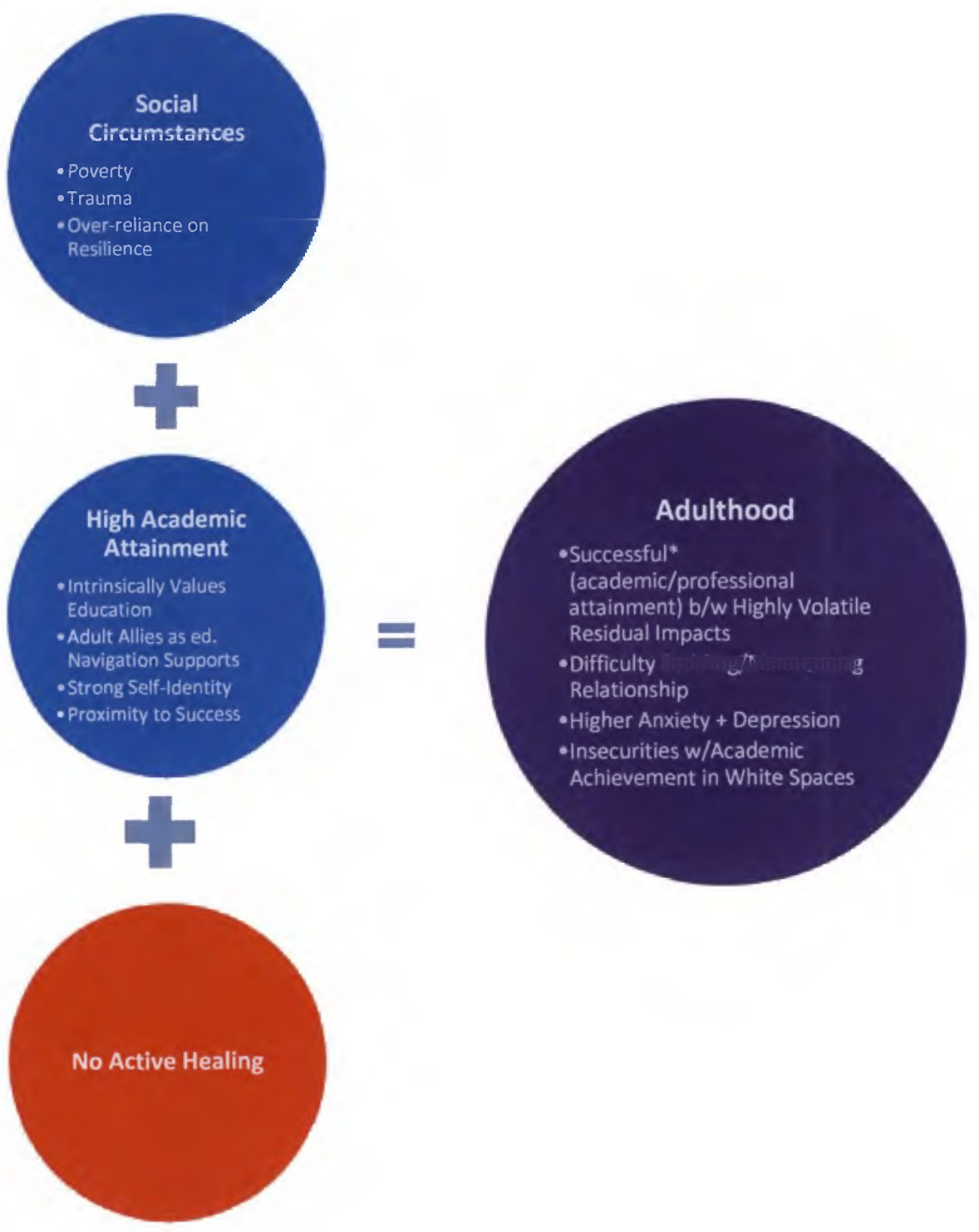
Those working with vulnerable populations such as the subjects of this study can view the BATT Phenomenon as an equation, displayed in Table 3.3. The next section of this chapter focuses on implications for practice both for education professionals and caretakers that help to decrease the likelihood of this phenomenon.

\section{Implications for Practice}

For professionals working with Black boys who grew up exposed to high amounts of stress, it is important to understand that in our case studies, survival skills were built amid trauma, and each subject experienced modest academic success from the coping skills they built to survive childhood. At no point in any of the testimonies from any of the subjects did they report any active healing or learning of different coping mechanisms as children. Therefore, it is important to underline that even if students seeing success from using tactics built during trauma, it is important to help these students develop healthier coping skills including some method of healing.

The second implication for RQ2 is that how Black men are loved matters, meaning each participant had someone love them while holding them accountable to being better men. In each case, the subject's significant other played a powerful role in helping mature the male subject. These wives helped refocus our subjects. They encouraged them to reach their goals while also being more emotionally healthy. The wives held high expectations for their husbands to be better men, and in each of the cases, the men responded positively. 
In looking at the implications for Black students, spouses can be replaced by any person that provides love and reciprocates trust to the child. In this context, reciprocated love is an active two-way, trusting relationship where two things are true: (1) person $\mathrm{A}$ is able to push person B (the subject) to their full capacity in a loving and caring way that promotes goals achievement as well as emotional well-being, and (2) person B is able to trust and receive that love. When thinking of this in the context of students, this person can be a myriad of different people the student trusts including coaches, a favorite teacher, an aunt, and so forth.

\section{Applying the Research: Educators}

There are several important lessons suggesting more effective educational strategies for teachers of Black boys. This study yielded a plethora of practical ways to utilize the data to both help Black male students achieve academically while avoiding the BATT Phenomenon. In this section, forms of application for two groups, educators and parent(s)/caretaker(s) are outlined. In conducting this study, a strong desire of this study was to conduct research that could be of service to Black parents struggling through a complicated education system. It is important to address parents and caretakers directly. In addressing educators, there are four applications of the research.

Avoid attempting to "teach grit" to Black students. The first application is for educators to know that the research suggests that teaching grit to Black students does not lead to academic achievement. The data from this study suggests that Black students impacted often show up already possessing grit. Educators should avoid "teaching grit". 
As discussed in Chapter 2, there is no actual evidence that grit is related to academic achievement in a meaningful way or that it can or should be used as an intervention to improve academic performance. Continuing to teach grit despite this knowledge is racist especially after having a better understanding of the known negative social-emotional impact it can have on Black students.

Be intentional about nurturing Black students' agency. The findings from the study suggest that nurturing the agency of Black students can help these students thrive later in life. Educators should aim to build skills that help students thrive without solely depending on the education system. Often for Black students, knowing how to utilize their environment to get the answer can be more important that just knowing the answer.

Ensure students leave your class whole with their self-worth intact. Educators should avoid exacerbating the false dichotomy that academic wellness must come at the expense of social-emotional wellness. Much of what was learned in the study was that each subject had experiences with educators that made direct attacks to their social emotional well-being. For example, Antwan was asked by his teacher (in front of his mother no less) if he was on drugs, Donald was physically removed from a class after (successfully) correcting a teacher, and Demarcus was abandoned by many of his college professors after his run-in with then-mayor Giuliani. These examples do not foster trust and support but reiterates that Black students are alone in these schools and college campuses. Those feelings of being alone or abandoned reinforces the notion that there is something wrong with them as Black boys. As a result, the Black boy hardens his 
emotions and consequentially loses parts of himself. This is the type of impact an educator can have on Black boys deeply impacted by trauma. In other words, this is one way educators act as perpetrators of Black boys leaving school systems broken. While the hope is to ensure Black students are being educated and having their social-emotional wellness thrive, at the very least, as educators, we need Black students to feel whole.

Be a good ally. Finally, if you cannot teach that one specific Black child, be honest. Being a good ally in this context means being honest with your students and lending your navigational capital to help ensure the best academic and social-emotional outcomes. Rather than constantly suspending, misdiagnosing, and/or criminalizing, partner with the student's parent(s) or caretaker(s), your school leadership, and community partners to thoughtfully plot out a course of action.

\section{Applying the Research: Parents and Caretakers}

This section helps parents and caretakers that are frustrated with the education system and are genuinely concerned for the academic and social emotional well-being of their child(ren). In this section, a variety of ways parents and caretakers can utilize the research such that do not leave their children's academic fate solely in the hands of ineffective school systems while also avoiding the BATT Phenomenon are outlined.

Fight for academic excellence in front of your children. The research from this study suggests that young children witnessing their parents fighting for better academic opportunities for them can potentially lead to a greater appreciation of quality education in the future. Whether fighting for quality education in front of your child means joining 
the local PTA or utilizing school choice for better options, a strong impression about the importance of education is made.

You are the expert on your child. Regardless of academic level, parents and caretakers must always see themselves as the leaders of their child's education and not cede their power to systems that have not historically served Black students well. Remain aware that Black boys are disproportionately misdiagnosed (Kunjufu, 2005; Noguera, 2002) and overmedicated (Kunjufu, 2005). The research suggests that with a vigilant caretaker, the fate of Black boys being wrongfully diagnosed can be avoided.

Understand that school houses are not the only spaces for academic and socialemotional wellness. As mentioned in Chapter 2, Black people have a communal history when it comes to educating their young. Since research shows Black children end up on the negative side of academic achievement in public schools, Black parents and caretakers should return to utilizing community organizations built with the specific goal of servicing the Black community. In practice, these organizations are Black religious spaces and community organizations such as the Boys Club. Black male scholars like King Jr. and Howard Thurman got their starts in the Black church. Conversely, Malcolm $\mathrm{X}$ and Muhammad Ali's scholarship was groomed through the Nation of Islam. Black prominent male figures such as Denzel Washington and Shaquille O'Neal credit much of their success to the Boys and Girls Club.

Focus significant attention on both academic and social-emotional wellness. When conversing with teachers about your child, ask questions specifically about 
academic achievement. Ask questions that go beyond your child just receiving a good grade. Find out if your child is reading on grade level. Ask if he or she are mastering math at grade level. If you sense that the teacher is unsure, first escalate your concerns to the school principal, then to the governing entity overseeing your child's school. Do the same for social-emotional wellness. Ask your child's teacher what your child is passionate about. Ask your child's teacher how your child deals with anger. Ask your child's teacher what their discipline policy is and invite them to partner with you around your child. This type of engagement helps disrupt the negative outcomes many Black children face in America's public schools.

This study highlighted the importance of dealing with extreme forms of trauma early in life and what can happen if this trauma goes unchecked. Youth that have experienced trauma must effectively try to heal to move forward in a healthy way. The research suggests that trauma may go dormant but reappear later in life if it is just avoided, like what is seen in each of our subjects.

\section{Recommendations for Future Research}

There is a need for further research to go deeper with a comprehensive mixedmethods approach on Black males with doctorate degrees impacted by the crack epidemic to determine their navigational strategies and to delve deeper into the BATT Phenomenon. By broadening the study to more than 100 participants, there is an opportunity to identify patterns and capture demographic information by region. The 
larger sample size could yield findings that are more generalizable across a variety of factors.

Interviews can be conducted to get a richer account of the navigation strategies that were deployed by these men. The interviews could also interrogate whether healing was present in their school settings and to what extent. From a deeper study, there would be a wealth of data to help better understand how Black males that grew up in extreme trauma went on to be successful.

In closing, this study highlights that Black males can learn even under dire circumstances. This study lifted the oral histories of Black men in ways not often seen in our society. The level of persistence and brilliance was evident in each of the three cases. The data gathered from this study also strongly suggests that depending on the school system to care for Black children the way they require may be futile, however, as a community, there must be an active push to improve the system for Black students while building our own navigation toolkit so families cannot just survive this broken system but thrive despite it. When children watch their parents actively prioritize education, whether it is by utilizing school choice, or actively advocating for their child's academics, it serves to help students begin to intrinsically value education. So much so, it helps to activate the student in a way that pays positive academic dividends. The goal is to concurrently focus on both a high-quality education and the high social-emotional wellbeing of our Black boys. 


\section{References}

Austin, C. C., Clark, E. M., Ross, M. J., \& Taylor, M. J. (2009). Impostorism as a mediator between survivor guilt and depression in a sample of African American college students. College Student Journal, 43(4).

Bazelais, P., Lemay, D. J., \& Doleck, T. (2016). How Does Grit Impact College Students' Academic Achievement in Science?. European Journal of Science and Mathematics Education, 4(1), 33-43.

Biernacki, P., \& Waldorf, D. (1981). Snowball sampling: Problems and techniques of chain referral sampling. Sociological methods \& research, 10(2), 141-163.

Boyce, C., \& Neale, P. (2006). Conducting in-depth interviews: A guide for designing and conducting in-depth interviews for evaluation input.

Brooms, D. (2015). "We didn't let the neighborhood win": Black male students" experiences in negotiating and navigating an urban neighborhood. The Journal of Negro Education, 84(3), 269-281.

Bronfenbrenner, U. (1986). Ecology of the family as a context for human development: Research perspectives. Developmental psychology, 22(6), 723.

Chang, W. (2014). Grit and academic performance: Is being grittier better? Open Access Dissertations. Paper 1306. 
Covarrubias, R., \& Fryberg, S. A. (2015). Movin'on up (to college): First-generation college students' experiences with family achievement guilt. Cultural Diversity and Ethnic Minority Psychology, 21(3), 420.

Covey, H. C., \& Eisnach, D. (2009). What the slaves ate: Recollections of African American foods and foodways from the slave narratives. ABC-CLIO.

Credé, M., Tynan, M. C., \& Harms, P. D. (2017). Much ado about grit: A meta-analytic synthesis of the grit literature. Journal of Personality and Social Psychology, 113(3), 492.

Croft Sr, W. E. (2017). The Mottf of Hope in African American Preaching during Slavery and the Post-Civil War Era: There's a Bright Side Somewhere. Lexington Books.

Duckworth, A. L., Peterson, C., Matthews, M. D., \& Kelly, D. R. (2007). Grit: perseverance and passion for long-term goals. Journal of personality and social psychology, 92(6), 1087.

Duncan, G. A. (2002). Beyond love: A critical race ethnography of the schooling of adolescent Black males. Equity \& Excellence in Education, 35(2), 131-143.

Duncan-Andrade, J. M. R., \& Morrell, E. (2008). The art of critical pedagogy: Possibilities for moving from theory to practice in urban schools (Vol. 285). Peter Lang. 
Ewing, K. M., Richardson, T. Q., James-Myers, L., \& Russell, R. K. (1996). The relationship between racial identity attitudes, worldview, and African American graduate students' experience of the imposter phenomenon. Journal of Black Psychology, 22(1), 53-66.

Freire, P. (1993). Pedagogy of the oppressed. New York: Continuum Press.

Fryer, R. G., Heaton, P. S., Levitt, S. D., \& Murphy, K. M. (2013). Measuring crack cocaine and its impact. Economic Inquiry, 51(3), 1651-1681.

Gilroy, P. (1993). The black Atlantic: Modernity and double consciousness. Verso.

Goodman, L. A. (1961). Snowball sampling. The annals of mathematical statistics, 148170.

Goodrick, D. (2014). Comparative case studies. Methodological briefs: Impact evaluation, 9 .

Ginwright, S., (2007). Black youth activism and the role of critical social capital in black community organizations. American Behavioral Sciences, 51, 403.

Gutman, L., Mcloyd, V. (2000). Parents' management of their children's education within the home, at school, and in the community: An examination of AfricanAmerican families living in poverty. The Urban Review, 32(1).

Harper, S. R. (2015). Success in these schools? Visual counternarratives of young men of 
color and urban high schools they attend. Urban Education, 50(2), 139-169.

Harris, P. C., Hines, E. M., Kelly, D. D., Williams, D. J., \& Bagley, B. (2014). Promoting the academic engagement and success of Black male student-athletes. The High School Journal, 97(3), 180-195.

Harris III, F., \& Wood, J. L. (2013). Student success for men of color in community colleges: A review of published literature and research, 1998-2012. Journal of Diversity in Higher Education, 6(3), 174.

Hart, S. A., Logan, J. A., Thompson, L., Kovas, Y., McLoughlin, G., \& Petrill, S. A. (2016). A latent profile analysis of math achievement, numerosity, and math anxiety in twins. Journal of educational psychology, 108(2), 181.

Ivcevic, Z., \& Brackett, M. (2014). Predicting school success: Comparing conscientiousness, grit, and emotion regulation ability. Journal of Research in Personality, 52, 29-36.

Johnson, L. P. (2017). The Status That Troubled Me: Re-Examining Work With Black Boys Through a Culturally Sustaining Pedagogical Framework. Urban Education, 52(5), 561-584.

Jordan, D., \& Wilson, C. (2015). Supporting African-American student success through prophetic activism: new possibilities for public school-church partnerships. Urban 
Education, 52(1), 91-119.

Kunjufu, J. (2005). Countering the conspiracy to destroy young black boys. Chicago, IL: African American Images.

Kunjufu, J. (2013). Changing school culture for Black males. Chicago, IL: African American Images.

Land, A., Mixon, J., Butcher, J., \& Harris, S, (2014). Stories of six African American males high school students: A qualitative study. NASSP Bulletin, 98(2), 142-162.

Lee, J. (2002). Racial and ethnic achievement gap trends: Reversing the progress toward equity?. Educational researcher, 31(1), 3-12.

Levin, B. (2009). Enduring issues in urban education. Journal of Comparative Policy Analysis, 11, 181-195.

McGee, E. (2013). Threatened and placed at risk: High achieving African American males in urban high schools. Urban Review, 45, 448-471.

Moll, L. C., Amanti, C., Neff, D., \& Gonzalez, N. (1992). Funds of knowledge for teaching: Using a qualitative approach to connect homes and classrooms. Theory into practice, $31(2), 132-141$.

Muenks, K., Wigfield, A., Yang, J. S., \& O'Neal, C. R. (2017). How true is grit? 
Assessing its relations to high school and college students' personality characteristics, self-regulation, engagement, and achievement. Journal of Educational Psychology, 109(5), 599.

Mutawah, A., \& Ali, M. (2015). The Influence of Mathematics Anxiety in Middle and High School Students Math Achievement. International Education Studies, 8(11), 239-252.

Noguera, P. A. (2003). The trouble with Black boys: The role and influence of environmental and cultural factors on the academic performance of African American males. Urban education, 38(4), 431-459.

Noguera, P. A. (2012). Saving Black and Latino boys: What schools can do to make a difference. Phi Delta Kappan, 93(5), 8-12.

Oberle, E., \& Schonert-Reichl, K. A. (2013). Relations among peer acceptance, inhibitory control, and math achievement in early adolescence. Journal of applied developmental psychology, 34(1), 45-51.

Parkin, J. R., \& Beaujean, A. A. (2012). The effects of Wechsler Intelligence Scale for Children-Fourth Edition cognitive abilities on math achievement. Journal of School Psychology, 50(1), 113-128.

Pogrow, S. (2018). Authentic quantitative analysis for education leadership decision 
making and Ed.D. dissertations: A practical, intuitive, and intelligible approach. Edition 2.2. ICPEL Press.

Pogrow, S. (In press, 2019). How practical significance misleads clinical practice: The case for switching to Practical Benefit to assess applied research findings. In Statistical inference in the 21st century: A world beyond $\mathrm{P}<0.05$. Schirm, A., Lazar, N. and Wasserman, R.L. (eds). The American Statistician.

Proehl, R. A., Ayon, L., Braganza, D., \& Sosa, G. A. (2017). De Marillac Academy: Perseverance, Purpose, and Promise. Journal of Catholic Education, 21(1), n1.

Rimfeld, K., Kovas, Y., Dale, P. S., \& Plomin, R. (2016). True grit and genetics: Predicting academic achievement from personality. Journal of personality and social psychology, 111(5), 780.

Ritchie, D. A. (1995). Doing oral history (pp. 1-10). New York: Twayne Publishers.

Sander, W. (2001). Chicago Public Schools and student achievement. Urban Education, 36(1), 27-38.

Sheppard, P. (2006). Successful African-American mathematics students in academically unacceptable high schools. Education, 126(4), 609-625.

Spencer, M. B. (2008). Lessons learned and opportunities ignored since Brown v. Board of Education: Youth development and the myth of a color-blind 
society. Educational Researcher, 37(5), 253.

Stewart, E. B. (2007). Individual and school structural effects on African American high school students' academic achievement. The High School Journal, 91(2), 16-34.

Strayhorn, T. L. (2014). What role does grit play in the academic success of black male collegians at predominantly white institutions?. Journal of African American Studies, 18(1), 1-10.

Sutton, D., \& Baker, R. F. (1990). Oakland Crack Task Force: A Portrait of Community Mobilization.

Tongco, M. D. C. (2007). Purposive sampling as a tool for informant selection. Ethnobotany Research and applications, 5, 147-158.

Tough, P. (2016). How kids learn resilience. The Atlantic, 317(5), 56-66.

West, M. R., Kraft, M. A., Finn, A. S., Martin, R. E., Duckworth, A. L., Gabrieli, C. F., \& Gabrieli, J. D. (2016). Promise and paradox: Measuring students' non-cognitive skills and the impact of schooling. Educational Evaluation and Policy Analysis, $38(1), 148-170$.

Wolters, C. A., \& Hussain, M. (2015). Investigating grit and its relations with college students' self-regulated learning and academic achievement. Metacognition and Learning, 10(3), 293-311. 
Zhou, M. (2003). Urban education: Challenges in educating culturally diverse children. Teachers College Record, 105, 208-225.

Zimmerman, E., \& Brogan, L. (2015). Grit and legal education. Pace L. Rev., 36, 114. 


\section{Appendix I \\ Implied Consent to Participate in Research}

Data collected from this confidential interview will be used for completion of a doctoral degree in Educational Leadership at San Francisco State University. The information gathered will be used for research on a dissertation study entitled: Beyond Grit and Resilience: How Black Men with Terminal Degrees Succeed Against the Odds.

The interview questions will be about your experience navigating public education as a male growing up during the crack epidemic.

You have been invited to participate because you are a Black male who now holds a terminal degree and was born between the years 1975 and 1990 that faced a multitude of severe circumstances and setbacks growing up in during the crack era.

You must be 18 years of age or older to participate. You may choose to participate or not. There is a risk that you might feel some discomfort in answering these questions, but you may stop participating at any time or you may request to skip any questions that you do not want to answer. If you do not wish to participate, you may simply tell that researcher that you do not want to participate, with no penalty to yourself. If you do participate, completion of the interview indicates your consent to the above conditions. Your decision whether or not to participate in this research will have no influence on your present or future status at San Francisco State University.

Please do not put your name on this form. The interview should take approximately 45 minutes to complete. Any questions or concerns should be directed to the researcher, Charles Cole, III at ccole@mail.sfsu.edu or the research advisor, Professor Shawn Ginwright at shawng@sfsu.edu. 


\section{Appendix II}

\section{Dissertation Study Sample Application}

This questionnaire will help us fill our study sample for the dissertation study entitled: Beyond Grit and Resilience:

How Black Men with Terminal Degrees Succeed Against the Odds

The purpose of this study is threefold; (1) to examine the strategies and navigation skills of four Black males, who against all odds, successfully navigated public education to attain a terminal degree; (2) to generate grounded theory about the relationship between poverty and agentive actions among black men with terminal degrees; and (3) to affirm and illuminate the lives of Black males that have succeeded academically.

Please fill out and we will be in touch with you soon.

Your responses to the questions below are completely confidential and will not be shared.

* Required

Name *

Your answer

Email *

Your answer

Phone number

Your answer

What city do you currently live in? *

Your answer

We are looking for Black males born between 1975 and 1990. What year were you born? *

Your answer

What is your doctorate degree in? * 
Your answer

Below are the cities most impacted by the crack epidemic. Please check all the cities you lived in during your $\mathrm{K}-12$ experience? * [Must be from one of the top 30 impacted cities listed below]
- LA
- New Orleans
- Memphis
- Philadelphia
- New York City
- Houston
- San Diego
- San Antonio
- Seattle
- Baltimore
- Portland
- Pittsburg (PA)
- Cleveland
- Cincinatti
- Detroit
- Chicago
- Minneapolis - Saint Paul
- Milwaukee
- St. Louis
- Atlanta
- Oakland
- Kansas City
- Miami
- Newark (NJ)
- Boston
- San Francisco
- Albany (NY)
- Buffalo
- Dallas
o Other:

This study focuses on the Black males overcoming obstacles. Please check all that apply and feel free to add options not listed below. ${ }^{*}$

- Lived in a shelter 
- Had a parent incarcerated

- Had a parent with substance abuse/addiction issues

- Had a parent die prematurely

- Had a close friend killed by violence

- Been a victim of gun violence

- Been incarcerated

- Had an Individualized Education Plan (IEP)

- Been expelled

- Transferred schools more than twice in an academic year

o Other:

In your own words, how were you personally impacted by the crack epidemic? Short hand is ok. *

Your answer

I have read the informed consent form attached here: http://bit.ly/ColeImpConsent *

Yes/No 
Appendix III

Research Methods Matrix

\begin{tabular}{|c|c|c|c|}
\hline $\begin{array}{l}\text { Research } \\
\text { Questions }\end{array}$ & $\begin{array}{l}\text { Data required to } \\
\text { answer } R Q\end{array}$ & $\begin{array}{l}\text { Method for } \\
\text { collecting data }\end{array}$ & $\begin{array}{l}\text { Exact procedure for } \\
\text { producing the data }\end{array}$ \\
\hline $\begin{array}{c}\text { (1) What } \\
\text { educational and } \\
\text { other } \\
\text { navigational } \\
\text { strategies do } \\
\text { Black men } \\
\text { impacted by the } \\
\text { crack epidemic } \\
\text { use to survive } \\
\text { public education } \\
\text { to achieve } \\
\text { doctorates? }\end{array}$ & $\begin{array}{l}\text { Tape recorded oral } \\
\text { accounts of African } \\
\text { American men } \\
\text { sharing their stories } \\
\text { of growing up, and } \\
\text { navigating their } \\
\text { ways to their } \\
\text { advanced degrees. } \\
\text { These accounts will } \\
\text { focus on three } \\
\text { types of stories- } \\
\text { childhood growing } \\
\text { up, the transition to } \\
\text { college, and the } \\
\text { pathway to an } \\
\text { advanced degree. }\end{array}$ & $\begin{array}{l}\text { The oral histories } \\
\text { focused on three } \\
\text { components of their } \\
\text { pathway to their } \\
\text { advanced degree. } \\
\text { First, the oral } \\
\text { history captured } \\
\text { stories about their } \\
\text { experiences } \\
\text { growing up in poor } \\
\text { communities. The } \\
\text { second theme } \\
\text { focused on } \\
\text { navigating } \\
\text { educational } \\
\text { challenges. The } \\
\text { third theme was } \\
\text { aimed at stories that } \\
\text { capture their stories } \\
\text { about unresolved } \\
\text { emotional scars } \\
\text { from their academic } \\
\text { achievement. }\end{array}$ & $\begin{array}{l}\text { First, background } \\
\text { research was } \\
\text { conducted on each } \\
\text { participant which } \\
\text { included history on } \\
\text { their neighborhood } \\
\text { and the impact crack } \\
\text { had on their specific } \\
\text { community. The goal } \\
\text { was to better } \\
\text { understand the } \\
\text { nuanced impact and } \\
\text { trauma ultimately } \\
\text { caused by the crack } \\
\text { epidemic coupled with } \\
\text { high levels of poverty. }\end{array}$ \\
\hline
\end{tabular}




\begin{tabular}{|c|c|c|c|}
\hline & $\begin{array}{l}\text { just how these men } \\
\text { navigated } \\
\text { education over the } \\
\text { years to attain } \\
\text { academic success } \\
\text { despite the } \\
\text { daunting obstacles } \\
\text { in their way. } \\
\\
\text { Get more in-depth } \\
\text { from specific parts } \\
\text { of the oral histories } \\
\text { given by } \\
\text { participants. }\end{array}$ & $\begin{array}{l}\text { to create more } \\
\text { questions and a } \\
\text { deeper analysis. } \\
\text { Construct an Oral } \\
\text { History for three } \\
\text { Black men that } \\
\text { grew up during and } \\
\text { directly after the } \\
\text { crack epidemic that } \\
\text { suffered great } \\
\text { personal setbacks } \\
\text { and hurdles to earn } \\
\text { a doctoral degree. } \\
\text { This is an } \\
\text { opportunity for } \\
\text { them to walk us } \\
\text { through their story } \\
\text { so that we may } \\
\text { better understand } \\
\text { all that they } \\
\text { endured on their } \\
\text { educational journey } \\
\text { and if there are any } \\
\text { lasting impacts, } \\
\text { positive or } \\
\text { negative. }\end{array}$ & $\begin{array}{l}\text { For interview one, the } \\
\text { central issues were } \\
\text { around navigating } \\
\text { early education, better } \\
\text { understanding the } \\
\text { subjects' family life, } \\
\text { and learning about any } \\
\text { traumas experienced. } \\
\text { For interview two, the } \\
\text { central issues centered } \\
\text { around navigating high } \\
\text { school and college } \\
\text { (undergraduate). } \\
\text { For interview three, } \\
\text { the central issues were } \\
\text { about navigating } \\
\text { graduate studies and } \\
\text { career. }\end{array}$ \\
\hline
\end{tabular}




\begin{tabular}{|c|c|c|c|}
\hline $\begin{array}{l}\text { RQ2: What are } \\
\text { the } \\
\text { unanticipated } \\
\text { social-emotional } \\
\text { residual effects } \\
\text { as a result of } \\
\text { rigid academic } \\
\text { achievement for } \\
\text { Black boys? }\end{array}$ & Same & $\begin{array}{l}\text { The oral history } \\
\text { was used as } \\
\text { a means to get as } \\
\text { personal and honest } \\
\text { with the participant } \\
\text { as possible. } \\
\text { Although there will } \\
\text { be general } \\
\text { questions, the idea } \\
\text { is allow these men } \\
\text { to open up and tell } \\
\text { their story about } \\
\text { their positive and } \\
\text { negative } \\
\text { experiences with } \\
\text { attending school } \\
\text { and how they } \\
\text { ultimately beat the } \\
\text { odds. }\end{array}$ & $\begin{array}{l}\text { Also in interview } \\
\text { three, the central } \\
\text { themes, in addition to } \\
\text { academic navigation, } \\
\text { included exploring any } \\
\text { residual social- } \\
\text { emotional effects from } \\
\text { the navigation and/or } \\
\text { traumas suffered along } \\
\text { the way. } \\
\\
\text { After each interview, } \\
\text { field notes were } \\
\text { recorded. There were } \\
\text { reflections around } \\
\text { what was heard to get } \\
\text { raw reactions. After all } \\
\text { three interviews were } \\
\text { completed for each } \\
\text { participant, the } \\
\text { interviews were sent } \\
\text { off to be transcribed. } \\
\text { Upon receipt of the } \\
\text { transcriptions, coding } \\
\text { occurred the data } \\
\text { under three themes: } \\
\text { Navigation, Trauma, } \\
\text { Residual Impact. } \\
\text { patterns. Then the } \\
\text { and identify various } \\
\text { utilized as an extra set } \\
\text { professors were } \\
\text { In the analysis, } \\
\text { colleagues and } \\
\text { to heyes to help code }\end{array}$ \\
\hline
\end{tabular}




\begin{tabular}{|l|l|c|}
\hline & $\begin{array}{c}\text { findings were recorded } \\
\text { for each participant } \\
\text { individually as well as } \\
\text { compared across the } \\
\text { case studies for any } \\
\text { themes or similarities } \\
\text { between all three } \\
\text { cases. This was } \\
\text { conducted for both } \\
\text { RQ1 and RQ2. } \\
\end{array}$ \\
\\
\end{tabular}




\section{Appendix IV \\ Navigation Strategies \& Residual Impacts \\ Individual Subjects}

\section{Demarcus, New York}

1. Proximity to success

2. Utilizing father figures when the father figure was absent

3. Utilizing school choice

4. Utilizing caring adults inside the school building

\section{Donald, Oakland}

1. Developing a strong sense of self-agency

2. Learning how to code-switch

3. Building relationships with adults w/academic success

4. Exercising school choice

\section{Antwan, Richmond}

1. Never too late to do the right thing

2. Support of a loving spouse

3. Being held to a higher standard

4. Wanting to set an example for those you love

\section{Collectively Across Subjects}

*Each subject eventually displayed huge amounts of academic agency. In their agentic make-up, these are the factors that were present across cases.

1. Sought out quality education

2. Strong Self-Identity

3. Came to intrinsically value education, wanted it for themselves

4. Proximity to success; gained their navigational skills through mentorship

\section{Residual Impacts}

Academic success comes at a cost for those that have been highly impacted by trauma, called the Black Achievement-Trauma Tax Phenomenon. They are left with deep emotional scars may include:

1. Latent emotional insecurity and heightened anxiety

2. Inability to build deep and meaningful relationships

3. Deep insecurity with academic achievement in white spaces 